\title{
Evaluation of Construction Site Noise to Allow the Optimisation of Construction Processes and Construction Machinery Selection
}

\author{
Radka Kantová
}

check for updates

Citation: Kantová, R. Evaluation of Construction Site Noise to Allow the Optimisation of Construction Processes and Construction Machinery Selection. Appl. Sci. 2021, 11, 4389. https://doi.org/10.3390/ app11104389

Academic Editor: Marek Pawełczyk

Received: 6 April 2021

Accepted: 10 May 2021

Published: 12 May 2021

Publisher's Note: MDPI stays neutral with regard to jurisdictional claims in published maps and institutional affiliations.

Copyright: (C) 2021 by the author. Licensee MDPI, Basel, Switzerland. This article is an open access article distributed under the terms and conditions of the Creative Commons Attribution (CC BY) license (https:/ / creativecommons.org/licenses/by/ $4.0 /)$.
Faculty of Civil Engineering, Brno University of Technology, Veveří 331/95, 60200 Brno, Czech Republic; kantova.r@fce.vutbr.cz

\begin{abstract}
During the pre-construction phase of an investment project, a construction plan is usually prepared by the building contractor. It contains financial plans, schedules, technical regulations with working procedures and proposals for the deployment of construction machinery and work teams. These items are then optimised in order to save money, shorten construction time and increase the quality of the final work while ensuring environmental and safety standards are maintained at the site. The ecological aspects of building work include compliance with the hygiene limits for building site noise, which is caused in particular by the simultaneous operation of machines. In the Czech Republic, limit values are set by Government Regulation 272/2011 Coll., as amended, on the protection of health against the adverse effects of noise and vibrations. The evaluation of construction site noise is not usually performed by contractors themselves and noise is usually measured only at the construction site, where work is limited or additional measures are taken in the case of values that exceed the stipulated limits. As the values in the construction plan should be as close as possible to reality during the implementation of the plan, it would seem appropriate to include such noise assessments within it. The purpose of this paper is to present an example of such an evaluation from the formal and material standpoint. The assessment has been conducted in the form of a specific noise study, expanded by a commentary on the treatment of the hypotheses. It shows how to obtain input data for evaluation, divide sub-calculations and use the supporting SW of the Hluk plus product for the purposes of construction information modelling, as well as how to correctly set noise sources and the positions of measured points for evaluation by the model within this programme. Subsequently, options for the evaluation of appropriate measures are listed, including their inclusion in reassessments.
\end{abstract}

Keywords: outdoor protected areas of buildings; construction information modelling; construction site noise; sources of noise; sound power level; sound pressure level; noise study; noise limit; isophone; noise barrier; building contractor; pre-production phase of a construction project; execution of a construction project

\section{Introduction}

The purpose of this paper is to describe the method for simulating the noise of construction machinery, as it should be performed by the contractor to protect people around the construction from noise while maintaining the highest possible involvement of construction machinery during construction.

In the case of excessive noise pollution, the selected machines, technical processes, or time of deployment of machines can be adjusted in the construction plan. Effective measures can be proposed in time for beneficial results to be achieved. The correct evaluation of construction noise and the abovementioned adjustments can help in optimising the planned building project and bringing the construction plan closer to its real implementation.

The construction plan prepared by the building contractor is based on the options available at the construction site and the volume of materials that must be brought to the 
site and then incorporated into the structures to be built there via appropriate technical procedures. The optimisation of such plans is conducted as an analysis of conflicting goals. Many contributions exist in the literature on the topic of optimisation performed to lower the cost of work, including the optimisation of construction site operation. Detailed procedures for the preparation and management of construction projects are described by a team of authors in the publication Př́prava a realizace staveb (Preparation and execution of construction) [1] and many other studies [2-4].

A proposal concerning construction site operations is provided by the contractor as part of their production and pre-production preparations for the construction project. The cost of the construction site equipment needed for standard structures should lie in the range of $2-5 \%$ of the total construction costs, as stated in Chapter 6 (Motyčka, V). Ref. [1] The costs of setting up a construction site also include the costs of necessary but unexpected measures taken during construction, which may include (for example) the installation of a noise barrier.

Heavy construction machines, especially lifting devices, have a decisive influence on the layout of a construction site and the sequence of the technical processes occurring there. The deployment of construction machinery is often analysed in a complex fashion and optimised, as it is the most expensive equipment at the construction site and the way it is used and combined has a major impact on the smoothness of the construction process. Various simulation models and optimisation methods are employed to achieve the effective use of machinery [3-5].

Today, ever more consideration is being given to ecological aspects during construction: Attention is paid to waste sorting, the washing of vehicle wheels before public roads are used and the reduction of dust and noise on building sites. During construction, the majority of noise is caused by machinery. Noise emanating from the site is added to noise from the operation of roads, railways and factories that already exist in the environment.

With regard to the ever-increasing intensity of noise emitted all around us, as well as the results of medical research, this issue has started to be monitored and limits have been defined for undesired sounds (noise) in relation to "indoor protected areas" (i.e., areas inside buildings), outdoor protected areas and the workplace. Efforts are being made to eliminate the adverse effects of noise on the human organism [2,6-8].

Excessive noise can temporarily break the nerve connections between the hair cells in the inner ear and the auditory nerve, causing hearing loss. This phenomenon is called "temporary hearing threshold shift" and will slowly disappear once the noise exposure is over. The re-generation of hearing can then take several hours to several days. It has been found that the shift of the hearing threshold starts already at noise levels exceeding $80 \mathrm{~dB}$. The pain threshold in humans occurs at about 120-130 dB. Noise can cause a number of health problems, not only hearing loss or deafness, but also stress, tinnitus, high blood pressure, headaches, physical exhaustion, difficulty concentrating, stomach and digestive problems, circulatory problems, sleep disorders, fast heartbeat, withdrawal peripheral blood vessels, increased adrenaline levels, loss of magnesium. According to research by the Regional Office of Public Health in Banská Bystrica, construction site noise is cited as the second most annoying set of unwanted sounds [2,9-12].

When we evaluate construction noise, i.e., noise from the operation of construction machinery on a building site that affects the surrounding area, the impact of noise at a line of facades of residential buildings in the surroundings of the site is investigated and so it falls within the set of limit values for outdoor protected areas [7].

The obligations for the constructor or building contractor are set by Act No. 258/2000 Coll. [6] on the protection of public health, which specifies in $\S 30$, par. 1, that a person who uses or operates machinery and devices which are sources of noise or vibration or whose operation creates noise (hereinafter only "sources of noise or vibration"), is obliged to ensure, via the taking of technical, organisational or other measures to the extent set by this act and legal regulation, that noise does not exceed legally regulated hygiene limits for protected outdoor areas, as well as protected indoor and outdoor areas of buildings and 
also prevent the above-limit transmission of vibration to natural persons [6-8]. Because of this, it is very advantageous for the contractor to know the future risks affecting the construction project they are preparing to execute.

The aim of this paper is to describe and determine in a case study partial methods for approaches to modelling and forecasting noise during construction site operation with a proposal for maximum time use of construction machinery while maintaining the limit values of noise per work shift. It is intended to lead to the introduction of building site noise emission evaluation as early as during the construction planning phase as part of production and pre-production preparations, when building contractors deal with the optimisation of technical processes, the sequence of technical construction processes and the deployment of machinery to meet the construction schedule.

The timely evaluation of construction site noise will enable the deployment of primary construction machines over time to be optimised in accordance with performance parameters, the required sequence of technical processes and economic parameters [3-5,13-20].

The presented case study, which features an explanation of the method used to produce it, is a guide to working with evaluations of building site noise which is of practical significance for contractors that need to process such evaluations. It documents how site noise can be determined in advance and also how noise control measures can be addressed in advance. Figure 1 shows a research scheme of the procedure in cases where it is necessary to address the noise from construction.

\begin{tabular}{|l|l|l|l|l|l|l|}
\hline $\begin{array}{l}\text { Setting the } \\
\text { boundary } \\
\text { conditions of the } \\
\text { investment work }\end{array}$ & $\begin{array}{l}\text { Modeling } \\
\text { of the production } \\
\text { space } \\
\text { of a building } \\
\text { and noise levels }\end{array}$
\end{tabular}

Figure 1. Reducing the value of construction site noise by modelling the production area of construction site and modifications of technological procedures during construction.

Figure 2 presents a graphically processed methodology of the possibility of access of the contractor to solve the noise from construction. The procedure presented in this case study, will show step by step the course of the optimal path to the implementation of new construction with compliance with the limits for noise from construction according to applicable legislation in the Czech Republic. The proposed solution consists in the preparation of documents for construction, the creation of its own model, which in the event of exceeding the limit values will be modified technological procedures, which are taken into account in the plan of future construction. The own construction will then take place without the risk of exceeding the noise limit values. During the construction, the values can be verified by measuring with a sound level meter. The conformity of the model and the real values can be assessed at the selected measuring points. However, it is also possible to measure values, for example inside buildings and to evaluate the attenuation by the perimeter cladding and other structures. Field measurements are not covered in this paper, but many studies are available [12,21-29]. 


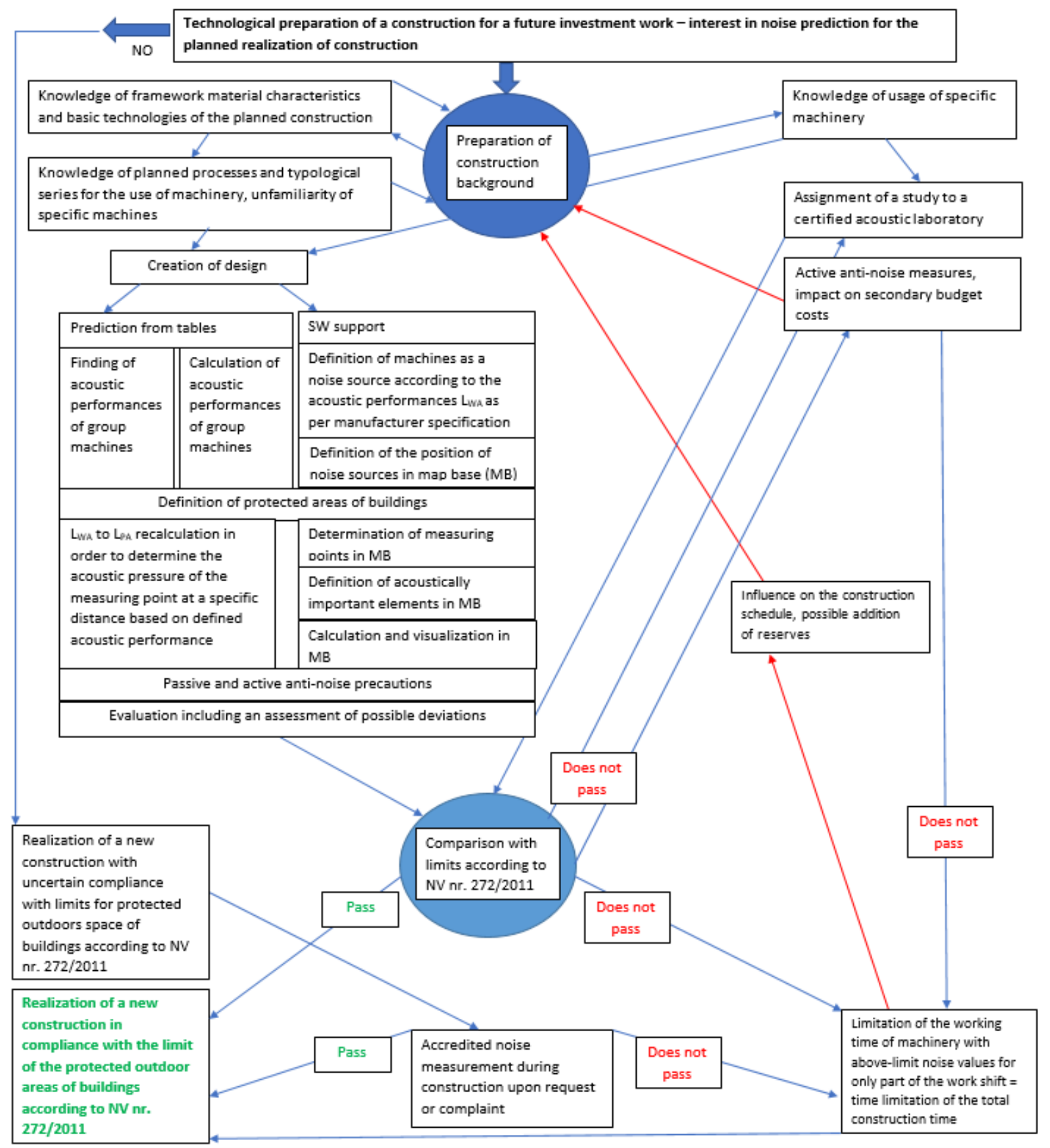

Figure 2. Methodology for noise prediction from construction activities.

\section{Materials and Methods}

To evaluate the noise from the construction of a planned investment project, the producer of the noise study needs to have the documentation for the project and the site plan (including the wider surroundings of the construction site) and the construction machinery required for the basic technical construction processes needs to be proposed. The evaluation concerning limit values in the context of Government Decree No. 272/2011 Coll. needs to be divided up in terms of the assessed time and corrections according to part $\mathrm{B}$ of this decree on construction site noise. The actual modelling takes place using Hluk plus software [30].

Due to the fact that Hluk plus is primarily used to model traffic noise, a special method is needed for modelling construction noise with regard to the sub-steps in the setting of the input conditions for the calculation [2]. 
The basis for the modelling itself is a plan of the site, which can be any available map [31], but should preferably be a precisely dimensioned drawing of the construction site facilities which is input into Hluk plus as a bitmap document. Subsequently, sources of noise with their values in $\mathrm{dB}$ are marked in the document, together with all acoustically significant elements and all measurement locations. The aim is to obtain values for places where evaluation is necessary with regard to the limit value of the calculation points.

The calculation itself and the plotting of isophone bands are modelled in sub-steps and always for specified combinations of machine assemblies working in parallel. In the case of a combination of machine assemblies for which a sound pressure value is above limit in one of the specified places, a new calculation is performed that incorporates measures that have been proposed to deal with the issue. Further evaluation cycles follow, incorporating further possible measures, until the limit values are met. At the end of the evaluation, all the proposed measures are quantified, after which they can then be transferred to other construction equipment planning documents.

\section{The Production of a Noise Study for the Evaluation of Construction Site Noise}

From the position of a building contractor, a noise study that evaluates construction noise is a model in which technical sources of noise are evaluated, not stochastic ones (random sources of noise during construction). Only airborne noise can be modelled, not noise that spreads through a structure. This model is fully sufficient for the purposes of construction equipment planning, as it enables above-limit sound pressure values to be considered and measures to be applied at the construction site. However, it does not provide proof of compliance with noise limits. Proof of compliance can only be obtained by directly measuring the noise emanating from noise sources. The competent body responsible for checking compliance with noise limits at a site is the local regional hygiene station. However, this body does not have the power to determine the specific noise reduction measures to be taken by the building contractor or constructor. The proposal of such measures and the provision of technical and financial support in order to take them must be done by the project contractor, who may incorporate their specific priorities for the proposed measures into the modelled situations during the production of the assessment. They can take into account, for example, the use of the technical equipment available to them, such as solid noise-reducing fence components or smaller machines with lower sound power levels. They can also use established contractual and partnership relationships to acquire an acoustic barrier or compare the financial cost of acquiring a soundproof wall with the financial loss incurred by extending the construction period, which usually involves a daily penalty for non-compliance with the construction deadlines stated in the work contract. When producing the noise study, the sources of uncertainties entered by the producer mainly consist of the input data, the adequacy of the calculation model with regard to the future real situation, the correctness of the calculation model and the procedure for checking risk points. When defining the input data, the real options for the deployment of suitable construction machines need to be checked, as the most suitable plant may not be available at a given place and time. It is necessary to read the sound power level values of the specific machine in question and not merely rely on general estimates based on the machine type or the machine manufacturer. It is necessary to look for conformity between all parameters in the technical sheet, as some machines are equipped with (for instance) a noise-absorbent engine cover and the sound power level of such modified machines is then lower. Another risk that may lead to incorrect setting of the input data is the marking of the positions of simultaneously operating machines at locations that are most unfavourable in relation to the measurement location. The machines move along assumed trajectories and correct positions on the trajectories must be selected for the given calculation in the model. The setting of the measurement points as a whole line of facades or as specific points needs to be entered correctly not only at the ground plan level but also and mainly for measurement heights, as different values can be measured at different heights at the same point. In front of a first-floor window, 
noise can be damped by, e.g., fencing and be below the limit, while on the second floor, the value can already be above the limit. The adequacy of the computational model in terms of the real future situation concerning equipment deployed at the site is determined by the quality of the map documentation, the layout of the equipment at the construction site and the understanding of technical processes of both the creator of the layout and the noise study producer. If operating, organisational and time considerations result in a different arrangement of objects and structures at the construction site and the proposed objects and structures were used as passive noise prevention measures in the noise study (e.g., the positioning of soils and loose materials in order for them to act as a noise barrier), there will be completely different transmissions of noise and an overall change in the acoustic situation for the environment. As far as formal flaws which can introduce uncertainty into the result are concerned, scale errors are possible when coupling the map and drawing materials in Hluk plus software. Annex No. 1 in the publication [2] can be used to ensure the correct procedure is followed when entering data into the software.

\subsection{The Content of a Noise study and the Principles Needed for Its Production}

\subsubsection{General Information}

This chapter presents subsidiary data from technical and accompanying reports and also other identifications relevant for the processing of a noise study. These are mainly the following data:

- The name of the construction project;

- The location of the construction project;

- The structure on the plot, its use;

- The subject of the project documentation;

- Division into structures;

- Information about the constructor;

- Information about the producer of the project documentation and chief designer;

- Information about the noise study producer;

- A list of input materials for the production of the noise study

\subsubsection{Legislation, Maximum Permissible Noise Values for the Construction Site}

The statement of parts, paragraphs and sections of the government regulation which will be applied in relation to the investigated noise case study, specifying the terminology related to issues concerning construction noise. The statement of whether the performance of construction work is being considered for other times than daytime. The description of noise indicators and the designation of evaluated periods. The explanation of the method of calculating the limit values for construction noise on the basis of the sum of basic sound pressure levels adjusted by corrections. At the end of this chapter, it is necessary to clearly state the sound pressure level value that is the limit against which the calculated values will be assessed.

3.1.3. Description of the Area in Terms of Acoustically Significant Elements and the Designation of Objects and Structures in Protected Outdoor Spaces around Buildings

A verbal description of the construction site in question is given here in relation to the map document which will be used; the verbal description supplements the information about the area from the perspective of the acoustics of significant elements which may affect the results of the calculation. Of particular importance is significant vegetation, changes in terrain elevation and structural elements which function as passive barriers against noise propagation, such as walls or fencing. In accordance with the legislation, a protected outdoor area is exactly defined as a line positioned $2 \mathrm{~m}$ in front of the windows of buildings, or as individual risk points. A list of points is provided for which the model will require sub-calculations in which the exact locations of objects are stated. 


\subsubsection{Sources of Noise during Construction Activities}

The main technical stages of the construction process must be determined from the project documentation. According to the structures which are to be built, i.e., their size, type, materials and the techniques used to construct them, sets of machines need to be designed, i.e., combinations of construction machines which will be deployed simultaneously in the given stages. During the process of construction work, acoustically significant activities and acoustically dominant machines will be determined and marked. Not only plant used for the construction itself will be included, but also machines for excavation and demolition, or recycling equipment. For all these expected sources of noise, the sound power level obtained either from the label of the machine or from its technical sheet [32], instruction manual or verified documents must be stated. Use can be made of Annex No. 4-The sound power level of construction machines, with the determination of the mean value of machine sets and the characteristics of the variability of the statistical set of the publication [2].

\subsubsection{Noise Calculations}

Sub-calculations with the Hluk plus software support are entered step by step, the aim being to obtain the sound power level of a group of machines. These groups must be marked and, for clarity, related to both the construction phase and the ongoing sub-process. For each sub-calculation, the acoustically significant influences which will be employed in the given calculation must be stated; these acoustically significant elements may change during the construction process. This is followed by the execution of the calculation and its comparison with the hygiene limit. The points at which this limit is exceeded must be clearly communicated. Subsequently, a second calculation is performed with the measure proposed to deal with the issue. The first measure to be tried is typically the separation of machine activities if the given construction technique or working procedure allows it. After performing the new calculation which takes the proposed measure into account, both the effectiveness of the measure and a repeated comparison of sound power levels with the limit need to be evaluated. There is no restriction on the number of recalculations that can be performed, so it is possible to incorporate the different options for passive as well as active measures gradually and keep repeating the calculation until a suitable result is achieved. If all the options for measures that can be applied in a given situation are exhausted, the last resort is to extend the duration of work by shortening the period when machines are simultaneously deployed during one shift.

\subsubsection{Conclusions of the Noise Study}

In the conclusions of the noise study, it is necessary to provide an overall evaluation. Although this evaluation is based on the sub-results of the individual calculations, it takes into account the meaningfulness of the measures in the context of the whole construction site. For example, if it is possible to reduce the sound pressure value below the limit by separating the work of the machines in the majority of calculations and we propose a noise barrier for one calculation at the same time, it will affect the situation in previous calculations and the separation of machines is no longer necessary. These connections need to be perceived and the situation needs to be assessed in a comprehensive and logical context with regard to the sub-results of the calculations.

\subsection{A Case Study-Assessment of Noise from the Construction of an Office Building}

\subsubsection{General Information}

With regard to GDPR, the names of natural and legal persons have been replaced only by initials in this chapter and no contact details are given.

Name of the structure: SIDLO SPOL. SM, Administrative building.

Location of the building: Mírová Street, Brno-Černovice 618 00, district Brno-Město, South Moravian Region.

Cadastral area, parcel No., area, type (culture) of land: Černovice. 
Structure on the plot, its use: The land is undeveloped. There is only a remnant of foundations laid for an unfinished house which will be removed.

Subject of the project documentation: The subject of the project documentation is an administrative building to be newly built for the company SM s.r.o., including transport and technical infrastructure as well as terrain modifications and landscaping. The building has a basement floor and two above-ground floors. It has an irregular floor plan and is covered by a flat roof with a height at the attic of $7.75 \mathrm{~m}$. Parking spaces are currently set up on the plot, with traffic access from Mírová Street. There are also utility network connections from Mírová Street.

Division into structures to be built:

- $\quad$ Structure SO 01-Administrative building

- $\quad$ Structure SO 02-transport and technical infrastructure (connections)

Information about the noise study producer:

- Ing. SH, CSc., Authorization: AI. for building structures, Czech Chamber of Chartered Engineers and Technicians Engaged in Construction

- Technical processing: Ing. Radka Kantová, Ph.D. Tel.: +420-605-584-948

List of input materials for the production of the noise study:

Accompanying report, Summarising technical report, Site drawing, Drawings of the new building SO01 from the SÍDLO SPOL project documentation. SM, Administrative building, maps for the area in question: www.cuzk.cz, www.mapy.cz (accessed on 20 September 2019).

Act No.258/2000 Coll. on the protection of public health, as amended.

Government Regulation 272/2011 Coll., on the protection of health against the adverse effects of noise and vibration, as amended.

\subsubsection{Legislation, Maximum Permissible Noise Values from Construction Sites}

The protection of human health against noise and vibration is covered in Act No. 258/2000 Coll. on the protection of public health, specifically in $\S \S 30-34$ of this act [6].

Government regulation No. 272/2011 Coll.

In accordance with these acts, Government Regulation No. 272/2011 on the protection of human health against the adverse effects of noise and vibration was issued on 24th August 2011 [7]. This regulation incorporates and enacts relevant European Union regulations and sets hygiene limits for noise and vibration in the workplace, along with methods for their determination and evaluation.

It sets, inter alia, the hygiene noise limits for protected outdoor and indoor areas of buildings and stipulates the manner in which noise and vibrations are to be measured and evaluated for daytime and night-time periods. In part three, $\S 12$ of this regulation, determining noise indicators are defined for the protected outdoor areas for which noise from adjacent construction sites is evaluated.

Of all the paragraphs in §12, paragraphs 1, 3 and 9 (quoted below) deal with construction noise, while the other paragraphs covering high-energy impulse noise, air traffic noise and old traffic noise load do not apply in this case. Night work is also not considered in this case.

The determining indicator of noise, with the exception of high-energy impulse noise, is the equivalent sound pressure level A LAeq,T and corresponding levels in the frequency bands. During the daytime it is determined for the 8 continuous and consecutive nosiest hours (LAeq, $8 \mathrm{~h}$ ), while at night it is for the noisiest $1 \mathrm{~h}$ (LAeq, $1 \mathrm{~h}$ ).

The hygiene limit for the equivalent level of sound pressure A, with the exception of air traffic noise and high-energy impulse noise, is determined as the sum of the basic sound pressure level A LAeq, T $50 \mathrm{~dB}$ and corrections taking into account the type of protected area as well as whether it is day or night-time, which are shown in Table 1, part A of Annex No. 3 to that regulation. For high impulse noise, an additional correction of $-12 \mathrm{~dB}$ is 
added. In the case of noise with tonal components, with the exception of traffic noise on roads and railways and from air traffic, another correction of $-5 \mathrm{~dB}$ is added.

Table 1. Corrections for the setting of hygiene noise limits in protected outdoor areas for noise from construction activities.

\begin{tabular}{cc}
\hline Evaluated Period [h] & Correction [B] \\
\hline FROM 06:00 & +10 \\
TILL 07:00 & +15 \\
FROM 07:00 & \\
TILL 21:00 & +10 \\
FROM 21:00 & \\
TILL 22:00 & +5 \\
FROM 22:00 & +5 \\
\hline TILL 06:00 & \\
\hline
\end{tabular}

The hygiene limit of the equivalent level of sound pressure A for noise from construction activities LAeq,s shall be determined by adding another correction to the hygiene limit for the equivalent sound pressure level A LAeq,T according to part B of Annex 3 to that regulation [7].

In part B of the Annex to that regulation, corrections for construction noise are stipulated: They are listed below in Table 1 .

Residential buildings are buildings which are used, even if only partly, for housing. The term "protected outdoor area of a building" means an area extending up to $2 \mathrm{~m}$ from a residential building, while a "protected outdoor area" is, according to Act No. 258/2000 Coll. as amended [6] an area which is used for recreation, sports, leisure or other activities.

According to the Government Decree, Part Three, Section 12, Articl 9 [7]. The basic sound pressure level for construction site noise LAeq,T is $50 \mathrm{~dB}$. Taking into account the corrections made according to the Annex to that regulation, noise limit values are calculated according to the type of noise.

A method of calculating the hygiene limit for noise from construction activity LAeq,s for a period shorter than $14 \mathrm{~h}$ :

LAeq, $\mathrm{s}=$ LAeq, T $50 \mathrm{~dB}+$ correction $7-2115 \mathrm{~dB}=65 \mathrm{~dB}$.

The hygiene limit for noise from construction activity for the daytime period from 7:00 till 21:00 is LAeq,s $=65 \mathrm{~dB}$.

Construction activities outside this period are not being considered for the studied construction project.

3.2.3. Description of the Area in Terms of Acoustically Significant Elements and Determination of Structures and Objects in the Protected Outdoor Space of Buildings

The investigated area is located between Mírová St and Černovická St, Brno-Černovice 618 00, Brno-Město district, South Moravian Region. The dimensions, location and shape of the plot correspond to the information in the project documentation [1], which states: The land intended for construction is approximately diamond shaped. The basic dimensions of the plot are approximately $16.3 \times 39.46 \mathrm{~m}$.

The map document for the modelling of the noise study in relation to the surrounding buildings is according to Figure 3. The protected outdoor area of the buildings is defined by the street line of Mirová St near the entrance to the construction site, which is between the buildings Mírová 25/9 and Mírová 237/11, with a width of approx. $15 \mathrm{~m}$ (noise will exit the construction site through it) and also the buildings neighbouring on the construction site (Mírová 25/9 25/7 on the right, Mírová 237/11 and 1231/13 on the left), which are oriented towards the garden area between Mírová St and Černovická St. In the garden behind Mírová 350/7a there is an acoustically significant strip of greenery which will be taken into account in the calculations. Two buildings that are near the construction site across Černovická Street are separated from the area in question by an embankment near the construction site as well as by a green belt and fencing on the side of the road near 
these buildings and they are not used for housing, so there is no protected outdoor area at that location.

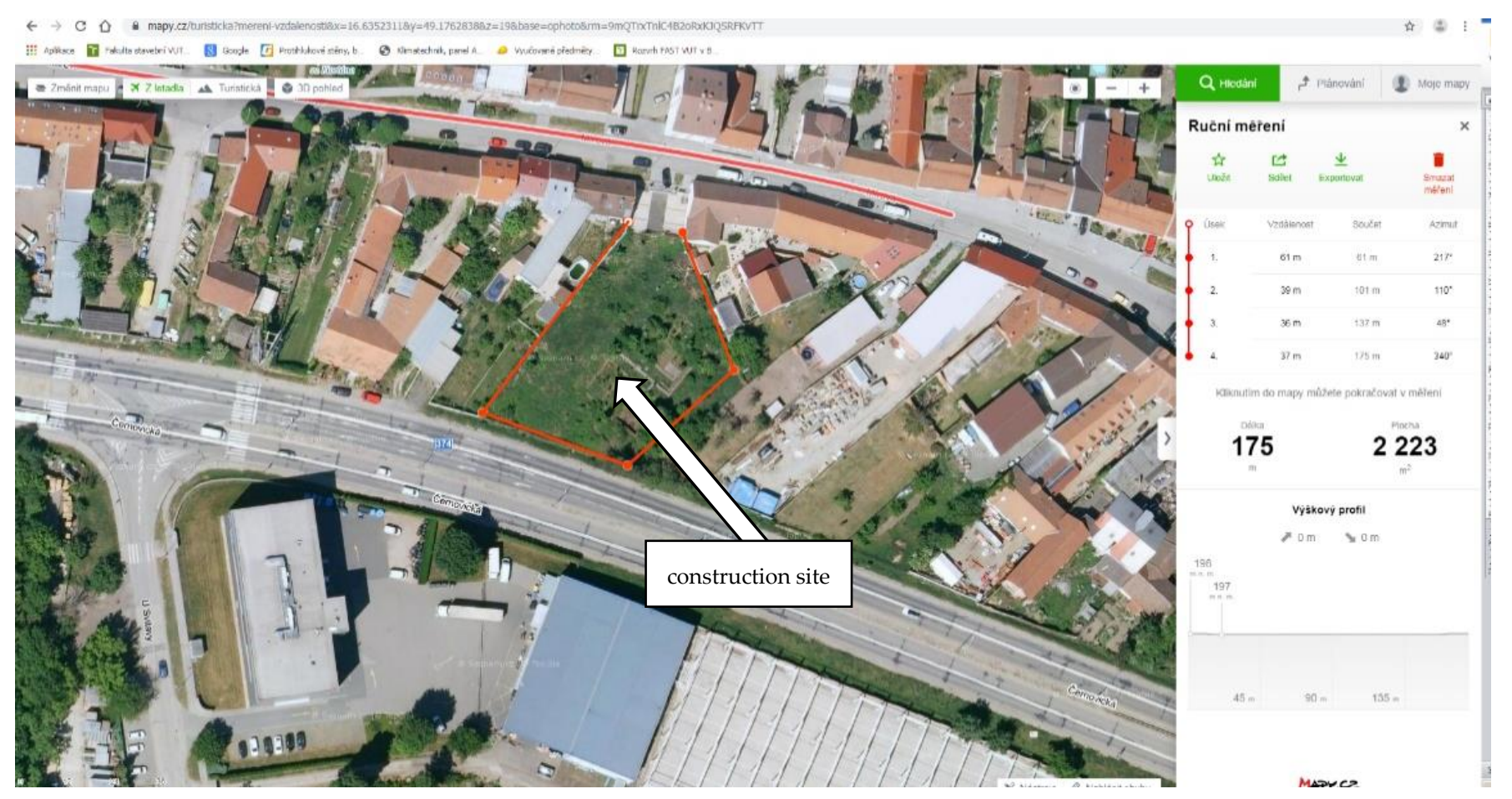

Figure 3. The area of the construction site and the area for the trajectories of construction machines during the construction of the investigated building project.

For the production of the noise study, the sound pressure values will be calculated for both facade lines of Mírová St and the facade line of buildings 25/9, 26/7, 350/7a and $237 / 11$, which are oriented towards the construction site.

These values will be compared with the limit according to Government Regulation 272/2011 Coll [7].

\subsubsection{Sources of Noise during Construction Activities}

According to the data presented in the summarising technical report, the execution of building SO01 is planned in four stages.

Earthworks: excavation of a construction pit, excavation of trenches, technical infrastructure.

The foundation of the building, rough substructure: foundation strips, foundation slab, waterproofing of the substructure.

Rough superstructure: lining of load-bearing walls and partitions, execution of the ceiling structure, roofing of the building.

Interior and finishing work: execution of plastering, painting, floors and all interiors.

Final landscaping and transport infrastructure on the plot.

Details, including the construction schedule, are planned in the next phase of the project documentation.

The calculation of noise from construction activities will be performed for the technical stages listed in the project documentation (except for interior and finishing works). With regard to the information from the accompanying and technical report on the demolition of the existing foundation strips, a demolition works stage will also be added.

For these stages, the parallel deployment of heavy construction plant at the site is expected due to the requirements of the given technological stages as well as the volume of work. As the construction work progresses, depending on the complexity of the given stage and the simultaneity of the involvement of acoustically dominant machines, the emitted noise will also change. The sound power level of a given machine is stated by the 
supplier in the technical sheet for the machine. The expected construction machines and their sound power levels are shown in Table 2.

Table 2. Expected sources of construction noise.

\begin{tabular}{ccc}
\hline & Sources of Noise & Sound Power Level (dB) \\
\hline 1. & Trucks & 90 \\
2. & Crawler excavators 12-40 tons & 103 \\
3. & Skid-steer loaders & 101 \\
4. & Crawler piling rig & 110 \\
& Excavator with a demolition hammer & \\
5. & Suspended hydraulic hammers, $\varnothing$ of the working & 114 \\
6. & tool up to 50 mm & 95 \\
7. & Mobile crane & 93 \\
8. & Construction lift & 106 \\
9. & Vibrating roller & 101 \\
10. & Concrete mixer truck & 97 \\
11. & Crawler excavators (mini) 0.9-9 tons & 100 \\
\hline
\end{tabular}

The most acoustically significant activities include demolition work, excavation and pile-driving work.

With regard to the phase of construction, the abovementioned plant will be deployed according to the necessary parallel processes and calculations will be entered as follows:

1. Demolition work: Removal of demolished material, machine 5, 3, 1

2. Earthworks for utility networks, machine 10, 3, 1

3. Earthworks: Excavations + excavated material removal, machine 2, 3, 1

4. Foundation of the building, deep foundations: pile-driving, machine $4,3,1$

5. Foundation of the building, shallow foundations: concreting, machine 9,11

6. Rough superstructure + material transfer, machine 6, 7

7. Final landscaping, machine 10,8

\subsubsection{Noise Calculations}

The following formula applies to the simultaneous operation of sources of noise:

$$
L_{v}=10 \lg \left(10^{\frac{L 1}{10}}+10^{\frac{L 2}{10}}+\ldots 10^{\frac{L n}{10}}\right)
$$

where $L_{1}$ to $L n$ are the sound power levels of the individual sources of noise and $L_{v}$ is the sound power level of a group of sources. This calculation will take place within one calculation entry in Hluk plus software and the sound pressure value at the measured point is calculated taking into account attenuation according to distance and with the influence of acoustically significant elements in the surroundings.

The input data for the calculation of the sound pressure level for the protected outdoor areas of buildings are sources of noise with the boundary conditions listed below.

In Figure 4, sound power levels are entered into the calculations for construction machines which are expected to be deployed in this type of construction project. They include parallel deployment according to the technical stages and materials required for the construction of the investigated structures. The calculation will be influenced by the surrounding structures, especially the buildings in the Mírová Street line and elements in the gardens between Mírová and Černovická St. Reflective surfaces of buildings, as well as acoustically significant absorbent green areas, are entered. The calculation takes the terrain into account, especially the embankment on Černovická St. The calculation of isophones for the display of colour bands is performed for a height of $1.5 \mathrm{~m}$ above the ground. The construction machines are considered to be stationary sources of noise. In the outdoor areas, specific acoustic pressure level values are entered and calculated at the calculation points $2.0 \mathrm{~m}$ in front of the facades of the buildings in question. 


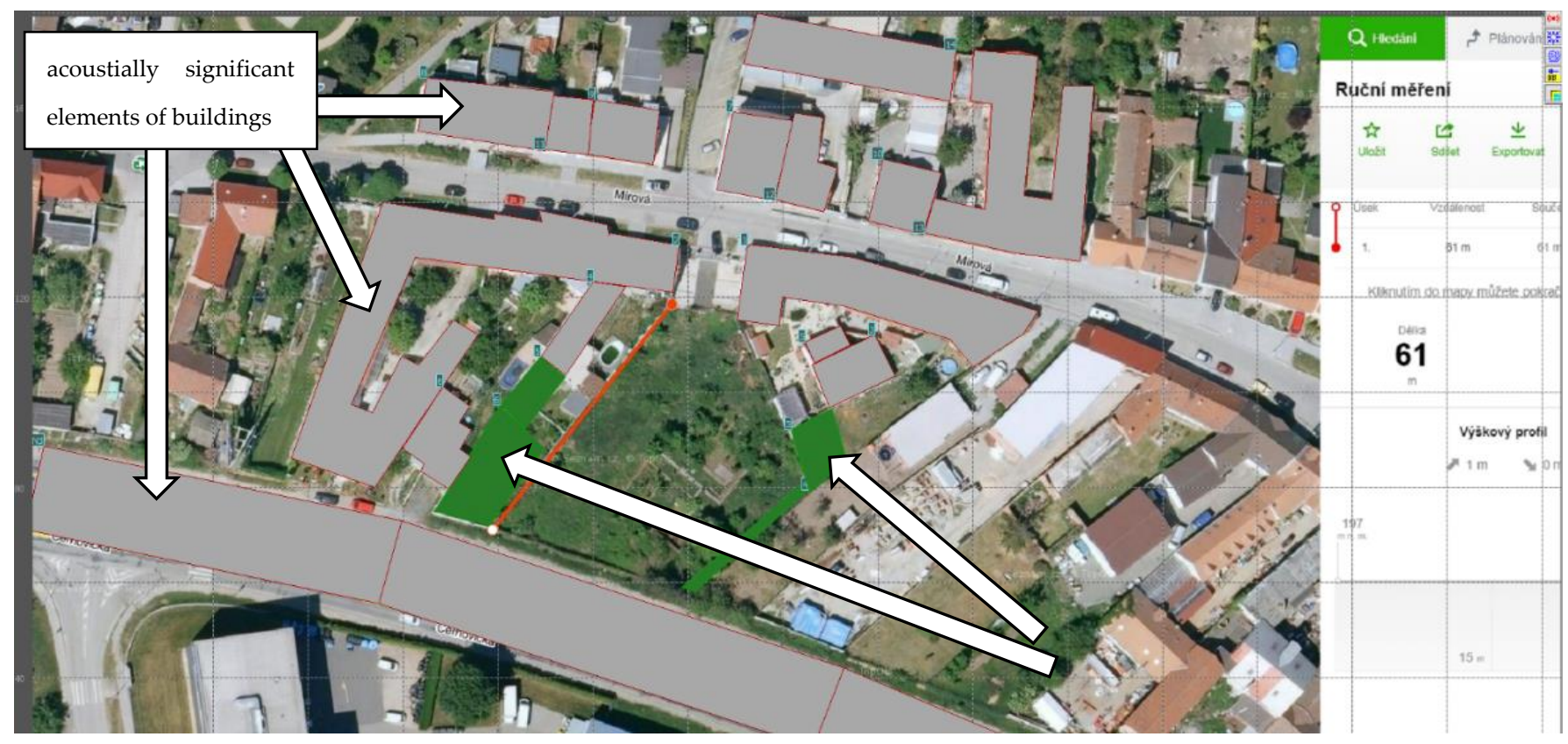

Figure 4. Acoustically significant elements in the investigated area.

Calculation 1: Demolition Work + Removal of Demolished Material, Machine: 5, 3, 1

The following is a modeling of the acoustic situation and calculations for noise sources listed in Table 3.

Table 3. Expected sources of construction noise.

\begin{tabular}{ccc}
\hline & Sources of Noise & Sound Power Level (dB) \\
\hline 1. & Trucks & 90 \\
5. & Excavator with a demolition hammer & 114 \\
3. & Suspended hydraulic hammers & 101 \\
\hline
\end{tabular}

In Figures 5 and 6, we see the marked construction sites as noise sources and measuring points in the model.

During the simultaneous deployment of machines, limit values are exceeded at four calculation points $(4,5,6,7)$ at the protected building facades, as we can see in Table 4 .

Measures: Separate deployment of machines. Removal of demolished material will take place when the main machine is not deployed.

By separating the demolition process itself from the removal of material excavated during demolition, the noise from the demolition itself is lowered (according to Table 5) by only a maximum of $0.4 \mathrm{~dB}$ and no significant decrease in noise levels is achieved. In addition, the limit values are exceeded at four calculation points $(4,5,6,7)$ at the protected building facades. 


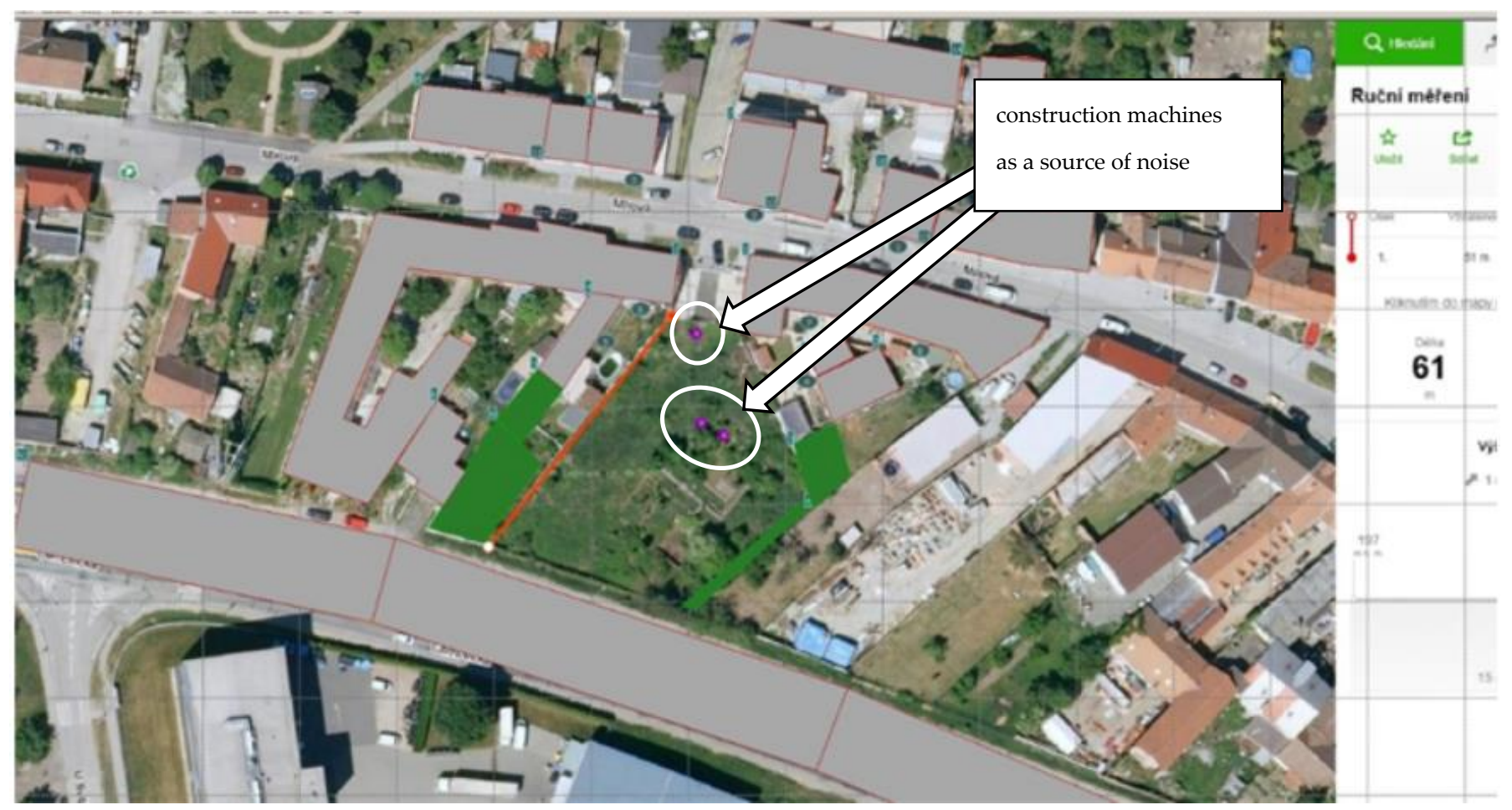

Figure 5. Acoustically significant elements of the investigated area, with the positions of construction machines as sources of noise, with simultaneous deployment.

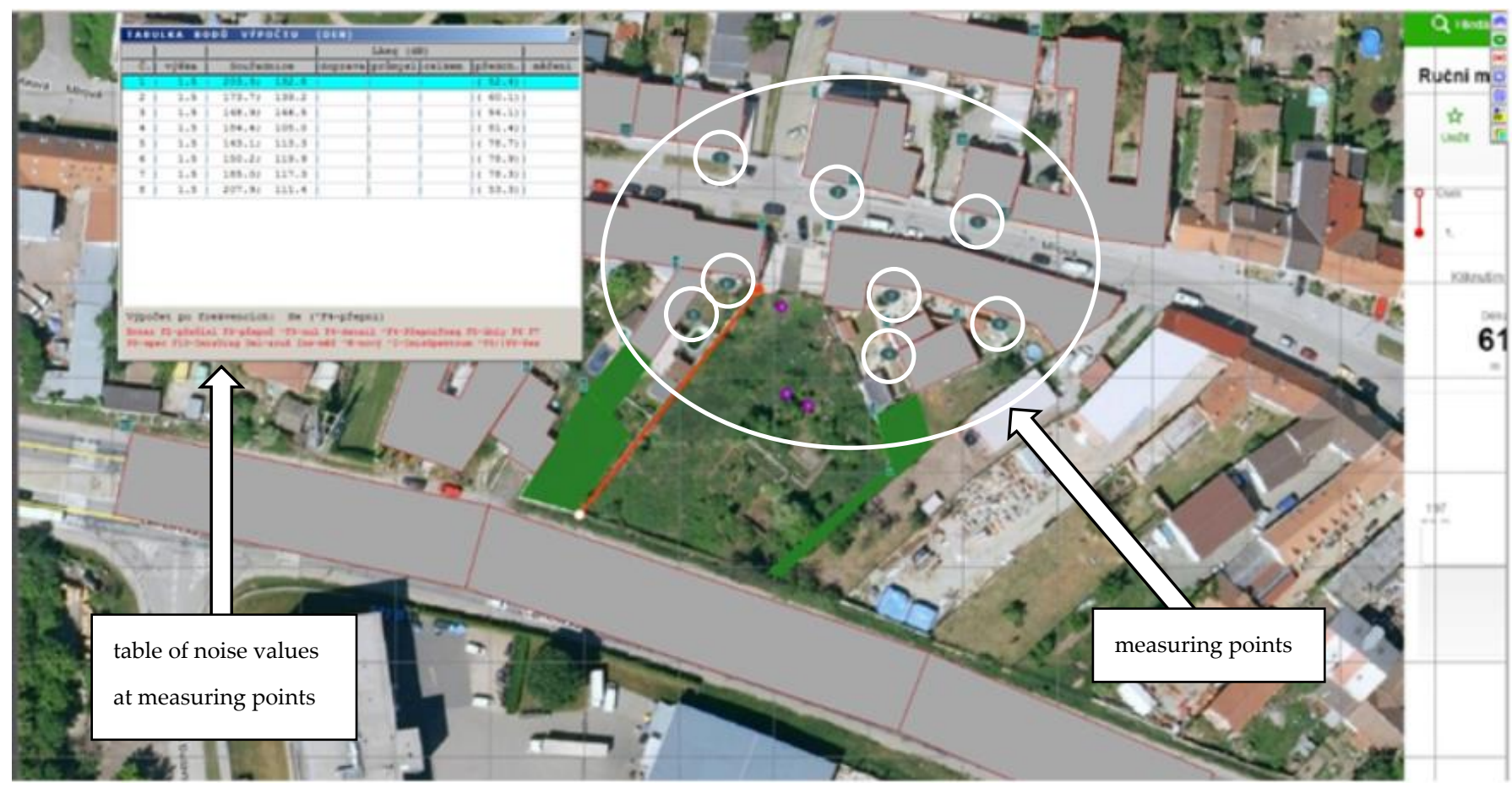

Figure 6. Acoustically significant elements of the investigated area, with the positions of construction machines as sources of noise, with simultaneous deployment and a table with values. 
Table 4. Table of calculated values of measured points for demolition work with the simultaneous deployment of machines.

\begin{tabular}{ccccc}
\hline No. & Height & \multicolumn{2}{c}{ Coordinates } & LA $_{\text {eq }}(\mathbf{d B})$ \\
\hline 1 & 1.5 & 203.3 & 132.8 & 52.4 \\
2 & 1.5 & 173.7 & 139.2 & 60.1 \\
3 & 1.5 & 148.9 & 146.5 & 54.1 \\
4 & 1.5 & 184.4 & 105.0 & $\mathbf{8 1 . 4}$ \\
5 & 1.5 & 143.1 & 113.3 & $\mathbf{7 8 . 7}$ \\
6 & 1.5 & 150.2 & 119.9 & $\mathbf{7 8 . 9}$ \\
7 & 1.5 & 185.0 & 117.3 & $\mathbf{7 8 . 3}$ \\
8 & 1.5 & 207.9 & 111.4 & 53.3 \\
\hline
\end{tabular}

Table 5. Table of calculated values of measured points for demolition work, with the separate deployment of machines.

\begin{tabular}{|c|c|c|c|c|c|c|}
\hline \multirow{2}{*}{ No. } & \multirow{2}{*}{ Height } & \multirow{2}{*}{\multicolumn{2}{|c|}{ Coordinates }} & \multicolumn{3}{|c|}{$\mathrm{LA}_{\mathrm{eq}}(\mathrm{dB})$} \\
\hline & & & & Industry & Total & Previous \\
\hline 1 & 1.5 & 203.3 & 132.8 & 52.1 & 52.1 & 52.4 \\
\hline 2 & 1.5 & 173.7 & 139.2 & 53.0 & 53.0 & 60.1 \\
\hline 3 & 1.5 & 148.9 & 146.5 & 53.2 & 53.2 & 54.1 \\
\hline 4 & 1.5 & 184.4 & 105.0 & 81.3 & 81.3 & 81.4 \\
\hline 5 & 1.5 & 143.1 & 113.3 & 78.3 & 78.3 & 78.7 \\
\hline 6 & 1.5 & 150.2 & 119.9 & 78.5 & 78.5 & 78.9 \\
\hline 7 & 1.5 & 185.0 & 117.3 & 78.2 & 78.2 & 78.3 \\
\hline 8 & 1.5 & 207.9 & 111.4 & 52.9 & 52.9 & 53.3 \\
\hline
\end{tabular}

Measures: The use of solid fencing is proposed.

A significant change in the acoustic situation will occur with the use of $1.8 \mathrm{~m}$ high solid fencing at the construction site and with solid gate wings at the entrance to the construction site. After this measure is applied, the calculation is only above-limit at the neighbouring plot next to Mírová 237/11, as is visible in Figure 7 and Table 6. Figure 7 also shows an enlarged scale for displaying $5 \mathrm{~dB}$ isophone bands.

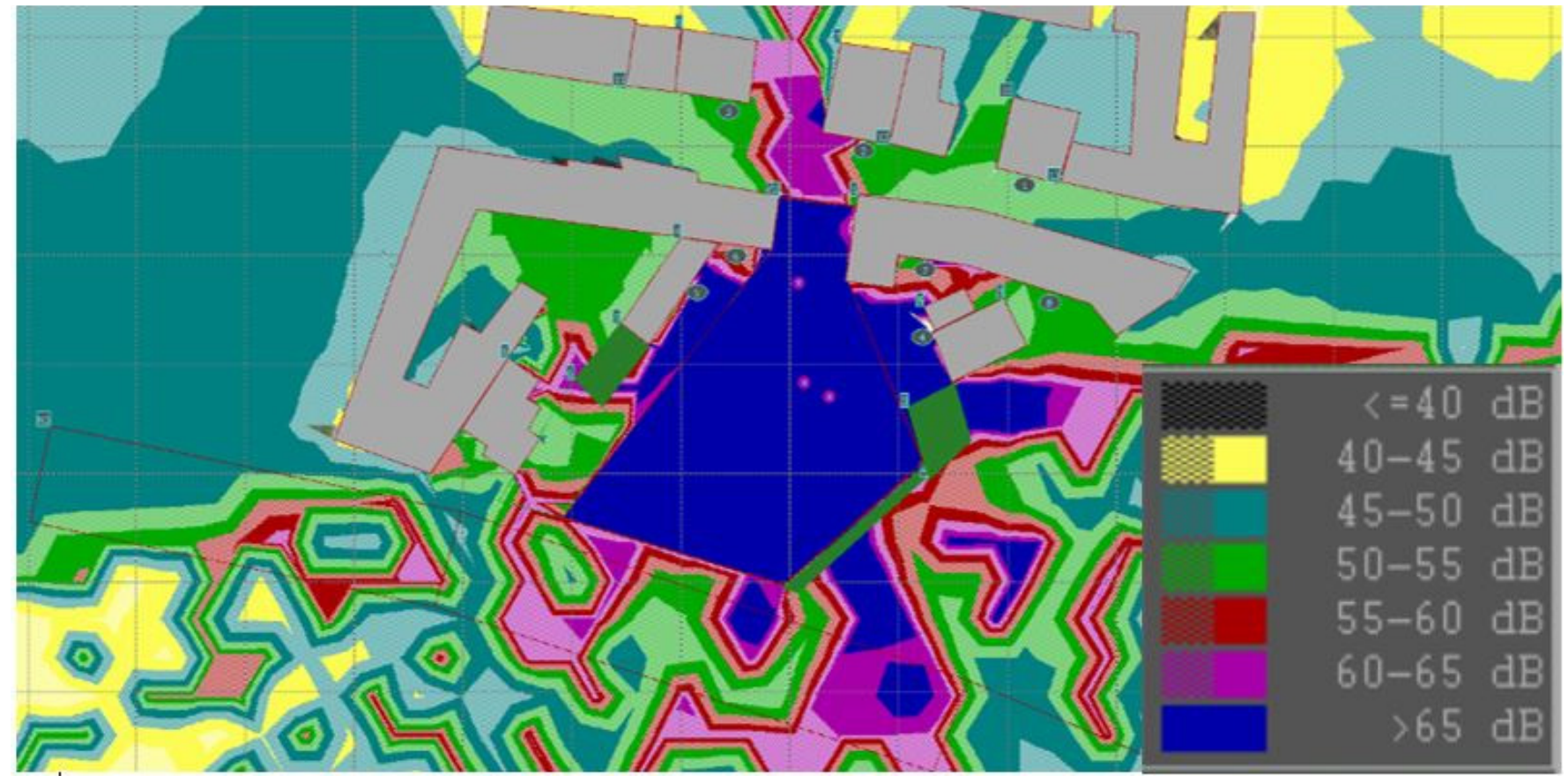

Figure 7. Colour representation of isophone bands after considering acoustically significant elements, including construction site fencing and a solid gate for the entrance to the construction site in the investigated area. 
Table 6. Table of calculated values of measured points for demolition work after considering acoustically significant elements, including construction site fencing and a solid gate for the entrance to the construction site in the investigated area.

\begin{tabular}{ccccccc}
\hline \multirow{2}{*}{ No. } & \multirow{2}{*}{ Height } & \multicolumn{2}{c}{ Coordinates } & \multicolumn{3}{c}{ LA $_{\mathbf{e q}}(\mathbf{d B})$} \\
\cline { 5 - 7 } & \multicolumn{2}{c}{203.3} & 132.8 & Industry & Total & Previous \\
\hline 1 & 1.5 & 173.7 & 139.2 & 52.1 & 52.1 & 52.1 \\
2 & 1.5 & 148.9 & 146.5 & 53.2 & 53.0 & 53.0 \\
3 & 1.5 & 184.4 & 105.0 & 58.4 & 53.2 & 53.2 \\
4 & 1.5 & 143.1 & 113.3 & 68.5 & 68.4 & 81.3 \\
5 & 1.5 & 150.2 & 119.9 & 55.0 & 55.0 & 78.3 \\
6 & 1.5 & 185.0 & 117.3 & 56.2 & 56.2 & 78.2 \\
7 & 1.5 & 207.9 & 111.4 & 52.9 & 52.9 & 52.9 \\
8 & 1.5 & & & & & \\
\hline
\end{tabular}

However, at measured point 5 , the noise value is still above limit.

Measures: The fulfilment of the hygiene limits for all measurement points can only be ensured by shortening the duration of demolition activities to $1 \mathrm{~h}=60 \mathrm{~min} /$ day, or to $7 \mathrm{~h}=420 \mathrm{~min} /$ day if solid fencing is used as an acoustic barrier.

Calculation 2: Earthworks for Utility Networks, Machine: 10, 3, 1

For the noise sources listed in Table 7 the modeling of the acoustic situation in Figure 8 follows, the calculation is shown in Table 8.

Table 7. Expected sources of construction noise.

\begin{tabular}{ccc}
\hline & Sources of Noise & Sound Power Level (dB) \\
\hline 10. & Crawler excavators (mini) 0.9-9 tons & 97 \\
3. & Skid-steer loaders & 101 \\
1. & Trucks & 90 \\
\hline
\end{tabular}

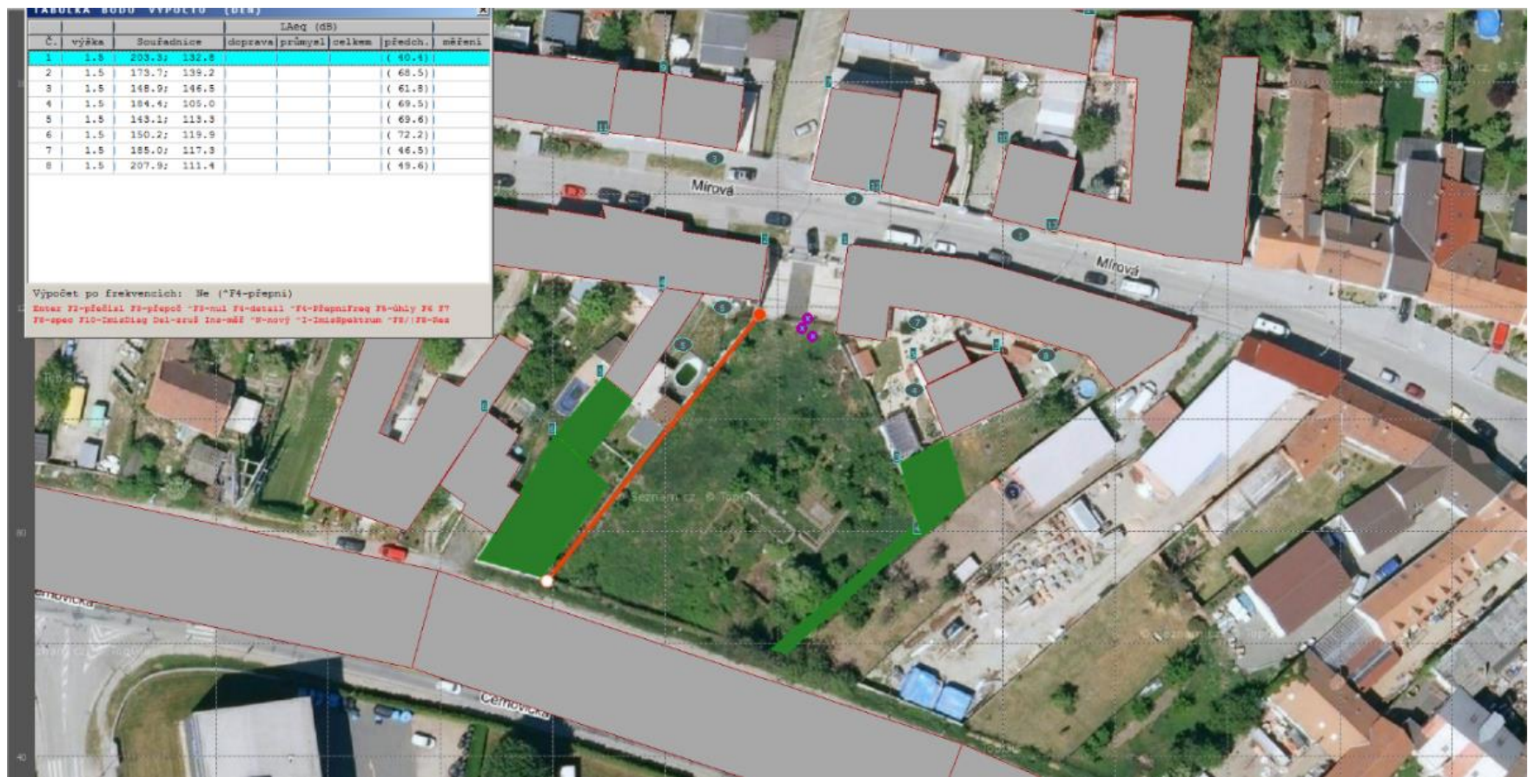

Figure 8. Acoustically significant elements (without construction site fencing or a solid gate) for earthworks during the construction of connections in the investigated area, with a table of values for the simultaneous deployment of machines. 
Table 8. Table of calculated values of measured points for earthworks during the execution of connections in the investigated area, with the simultaneous deployment of machines.

\begin{tabular}{ccccc}
\hline No. & Height & \multicolumn{2}{c}{ Coordinates } & LA $_{\mathbf{e q}}(\mathbf{d B})$ \\
\hline 1 & 1.5 & 203.3 & 132.8 & 40.4 \\
2 & 1.5 & 173.7 & 139.2 & $\mathbf{6 8 . 5}$ \\
3 & 1.5 & 148.9 & 146.5 & 61.8 \\
4 & 1.5 & 184.4 & 105.0 & $\mathbf{6 9 . 5}$ \\
5 & 1.5 & 143.1 & 113.3 & $\mathbf{6 9 . 6}$ \\
6 & 1.5 & 150.2 & 119.9 & $\mathbf{7 2 . 2}$ \\
7 & 1.5 & 185.0 & 117.3 & 46.5 \\
8 & 1.5 & 207.9 & 111.4 & 49.6 \\
\hline
\end{tabular}

During the simultaneous deployment of all the needed machines, the limit values are exceeded at measured points 2, 4, 5, 6 .

Measures: Separate the excavation process and the removal of excavated material into separate cycles.

In Figure 9, we see a table in the upper left corner, which is then enlarged and rewritten in Table 9.

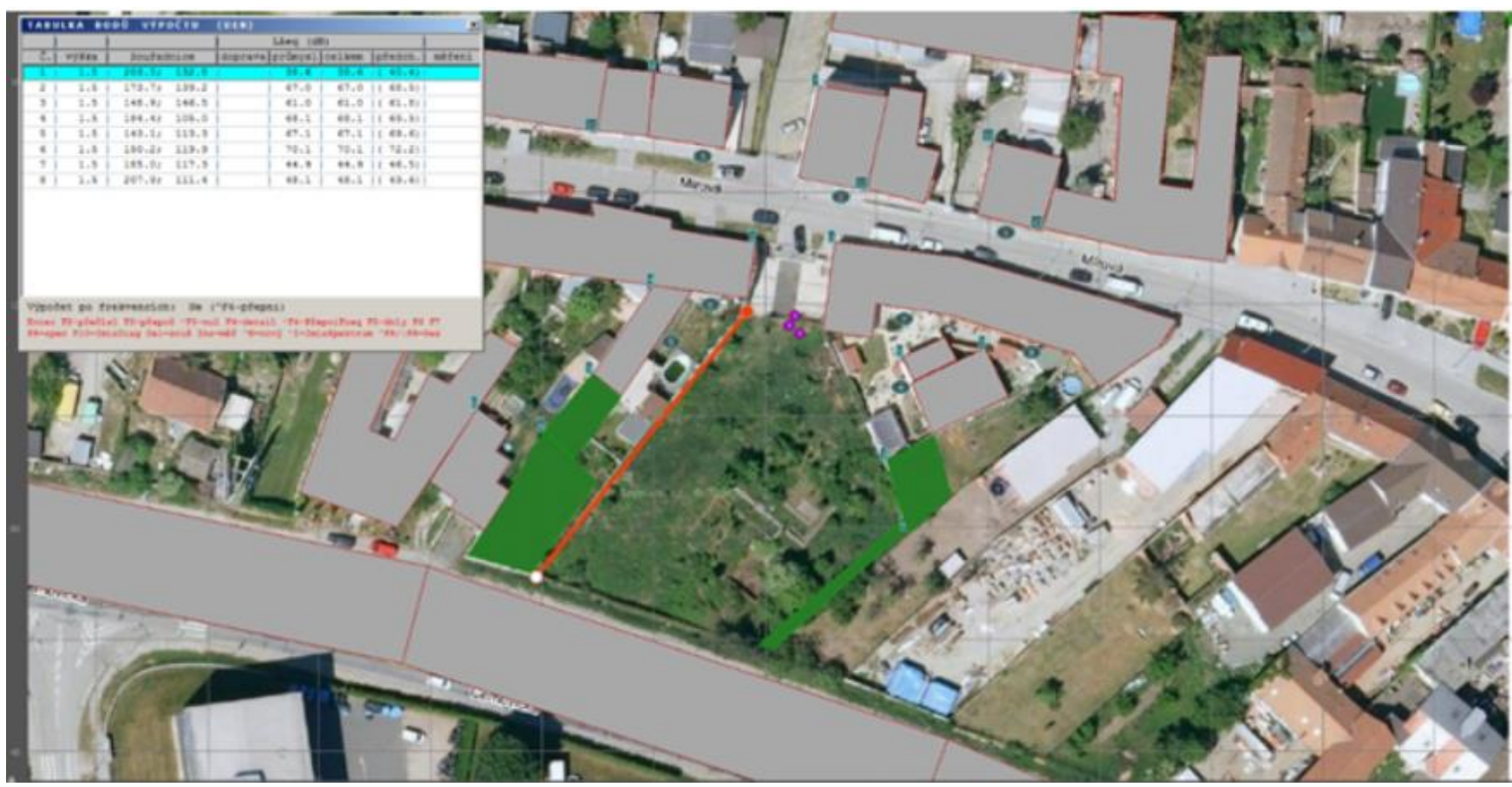

Figure 9. Acoustically significant elements (without construction site fencing or a solid gate) for earthworks during the execution of connections in the investigated area, with a table of values.

The separation of the excavation process from material removal does not reduce the values at the calculation points sufficiently and the limit values are exceeded at four calculation points $(2,4,5,6)$.

Measures: The hygiene limit can only be fulfilled by shortening the period of excavation activities to $3 \mathrm{~h}=180 \mathrm{~min} /$ day.

Fencing of the construction site during the construction of connections is not expected. 
Table 9. Table of calculated values of measured points with the simultaneous deployment of machines shown as previous values; after the separation of excavation work from material removal, the values shown are only for excavations with an excavator.

\begin{tabular}{|c|c|c|c|c|c|c|}
\hline \multirow{2}{*}{ No. } & \multirow{2}{*}{ Height } & \multirow{2}{*}{\multicolumn{2}{|c|}{ Coordinates }} & \multicolumn{3}{|c|}{$\mathrm{LA}_{\mathrm{eq}}(\mathrm{dB})$} \\
\hline & & & & Industry & Total & Previous \\
\hline 1 & 1.5 & 203.3 & 132.8 & 38.6 & 38.6 & 40.4 \\
\hline 2 & 1.5 & 173.7 & 139.2 & 67.0 & 67.0 & 68.5 \\
\hline 3 & 1.5 & 148.9 & 146.5 & 61.0 & 61.0 & 61.8 \\
\hline 4 & 1.5 & 184.4 & 105.0 & 68.1 & 68.1 & 69.5 \\
\hline 5 & 1.5 & 143.1 & 113.3 & 67.1 & 67.1 & 69.6 \\
\hline 6 & 1.5 & 150.2 & 119.9 & 70.1 & 70.1 & 72.2 \\
\hline 7 & 1.5 & 185.0 & 117.3 & 44.9 & 44.9 & 46.5 \\
\hline 8 & 1.5 & 207.9 & 111.4 & 48.1 & 48.1 & 49.6 \\
\hline
\end{tabular}

Calculation 3: Earthworks: Excavations + Material Removal, Machine 2, 3, 1

For the noise sources listed in Table 10, the acoustic situation is modeled in Figure 10, the calculation is given in Table 11.

Table 10. Expected sources of construction noise.

\begin{tabular}{ccc}
\hline & Sources of Noise & Sound Power Level (dB) \\
\hline 1. & Trucks & 90 \\
2. & Crawler excavators $12-40$ tons & 103 \\
3. & Skid-steer loaders & 101 \\
\hline
\end{tabular}

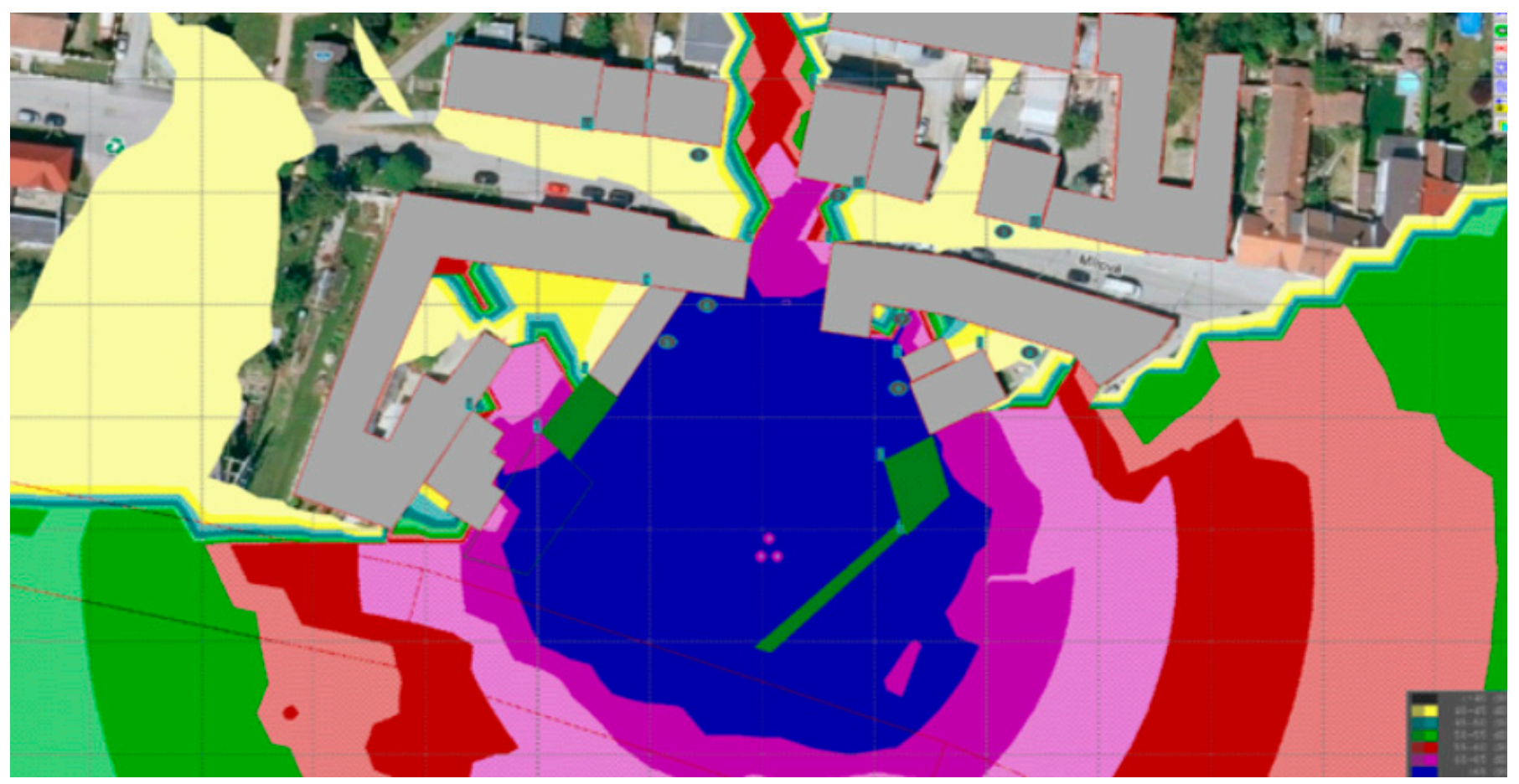

Figure 10. Colour map of isophone bands after the consideration of acoustically significant elements (without construction site fencing or a solid gate) for earthworks in the investigated area. 
Table 11. Table of points from the calculation of measured points for earthworks in the investigated area.

\begin{tabular}{cccccc}
\hline \multirow{2}{*}{ No. } & \multirow{2}{*}{ Height } & \multicolumn{2}{c}{ Coordinates } & \multicolumn{2}{c}{ LA $_{\text {eq }}(\mathbf{d B})$} \\
\cline { 5 - 6 } & & 203.3 & 132.8 & Industry & Total \\
\hline 1 & 1.5 & 173.7 & 139.2 & 57.9 & 40.9 \\
2 & 1.5 & 148.9 & 146.5 & 42.2 & 57.6 \\
3 & 1.5 & 184.4 & 105.0 & 68.0 & 42.2 \\
4 & 1.5 & 143.1 & 113.3 & 67.4 & $\mathbf{6 8 . 0}$ \\
5 & 1.5 & 150.2 & 119.9 & 66.6 & $\mathbf{6 7 . 4}$ \\
6 & 1.5 & 185.0 & 117.3 & 65.1 & $\mathbf{6 5 . 6}$ \\
7 & 1.5 & 207.9 & 111.4 & 41.4 & 41.4 \\
8 & 1.5 & & & &
\end{tabular}

The hygiene limit is exceeded at measured points $4,5,6,7$.

Measures: Propose solid fencing for the construction site.

The limit can be met using the solid fencing previously installed for the excavation phase. Figure 11 shows a color map of isophone bands after considering acoustically significant elements with site fencing and a fixed gate for earthworks in the study area, where we see in Table 12 that the values do not exceed the limit.

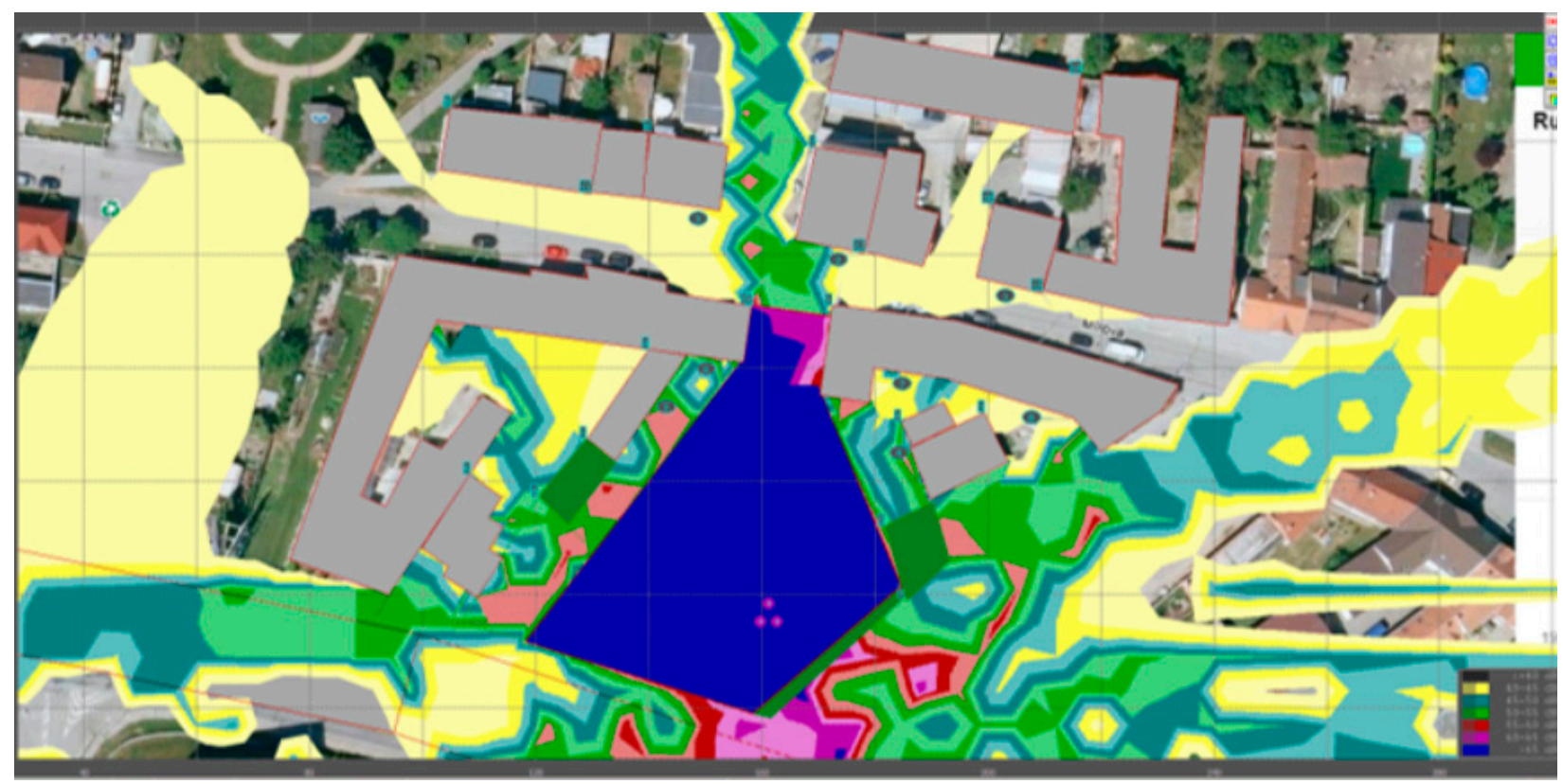

Figure 11. Colour map of isophone bands after the consideration of acoustically significant elements with construction site fencing and a solid gate for earthworks in the investigated area.

Table 12. Table of calculated values of measured points for earthworks with construction site fencing and a solid gate in the investigated area.

\begin{tabular}{ccccccc}
\hline \multirow{2}{*}{ No. } & \multirow{2}{*}{ Height } & \multicolumn{2}{c}{ Coordinates } & \multicolumn{3}{c}{ LA $_{\mathbf{e q}}(\mathbf{d B})$} \\
\cline { 5 - 7 } & \multicolumn{2}{c}{203.3} & 132.8 & Industry & Total & Previous \\
\hline 1 & 1.5 & 173.7 & 139.2 & 40.9 & 40.9 & 40.9 \\
2 & 1.5 & 148.9 & 146.5 & 42.2 & 42.0 & 57.6 \\
3 & 1.5 & 184.4 & 105.0 & 44.7 & 42.2 & 42.2 \\
4 & 1.5 & 143.1 & 113.3 & 44.2 & 44.7 & 68.0 \\
5 & 1.5 & 150.2 & 119.9 & 44.3 & 44.3 & 67.4 \\
6 & 1.5 & 185.0 & 117.3 & 42.5 & 42.5 & 66.6 \\
7 & 1.5 & 207.9 & 111.4 & 41.5 & 41.5 & 41.4 \\
8 & 1.5 & & & & & \\
\hline
\end{tabular}


After this measure is taken, the hygiene limits for the earthworks stage are fulfilled. Without fencing the work period has to be shortened to $6.5 \mathrm{~h}=390 \mathrm{~min} /$ day.

Calculation 4: Foundation of the Building, Deep Foundations-Pile-Driving, Machine: 4, 3, 1

The following is a modeling of the acoustic situation and calculations for noise sources listed in Table 13.

Table 13. Expected sources of construction noise.

\begin{tabular}{ccc}
\hline & Sources of Noise & Sound Power Level (dB) \\
\hline 1. & Trucks & 90 \\
3. & Skid-steer loaders & 101 \\
4. & Crawler piling rig & 110 \\
\hline
\end{tabular}

The position of the piling rig in Figure 12 is considered the riskiest position with regard to the developed areas of Mírová St., the resulting values are shown in Table 14.

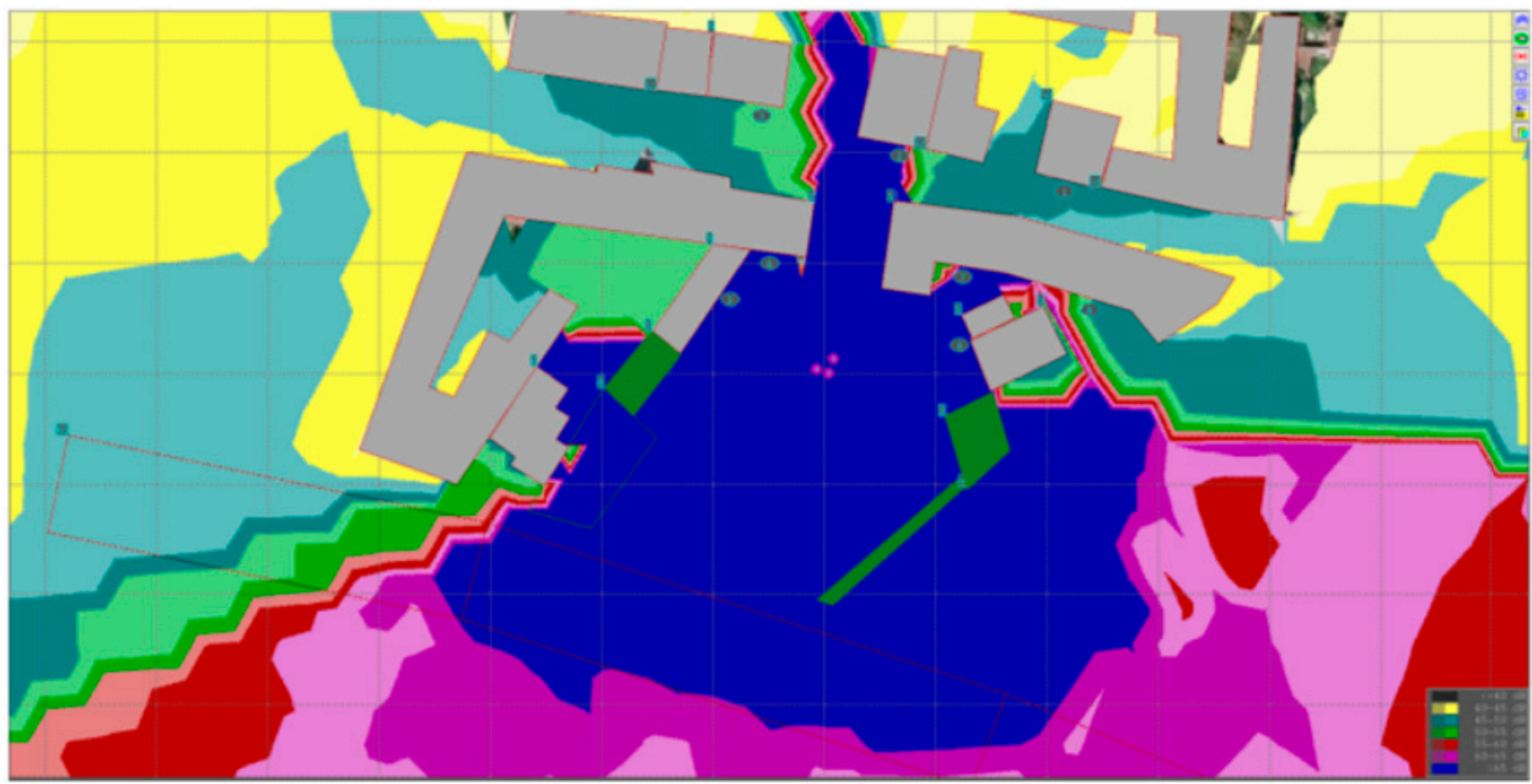

Figure 12. Colour map of isophone bands after considering acoustically significant elements (without construction site fencing or a solid gate) for pile-driving work in the investigated area.

Table 14. Table of points from the calculation of measured points for earthworks without construction site fencing or a solid gate for pile-driving work in the investigated area.

\begin{tabular}{|c|c|c|c|c|c|c|}
\hline \multirow{2}{*}{ No. } & \multirow{2}{*}{ Height } & \multirow{2}{*}{\multicolumn{2}{|c|}{ Coordinates }} & \multicolumn{3}{|c|}{$\mathrm{LA}_{\mathrm{eq}}(\mathrm{dB})$} \\
\hline & & & & Industry & Total & Previous \\
\hline 1 & 1.5 & 203.3 & 132.8 & 48.6 & 48.6 & 48.9 \\
\hline 2 & 1.5 & 173.7 & 139.2 & 71.8 & 71.8 & 62.8 \\
\hline 3 & 1.5 & 148.9 & 146.5 & 50.2 & 50.2 & 50.2 \\
\hline 4 & 1.5 & 184.4 & 105.0 & 77.2 & 77.2 & 66.7 \\
\hline 5 & 1.5 & 143.1 & 113.3 & 77.6 & 77.6 & 56.6 \\
\hline 6 & 1.5 & 150.2 & 119.9 & 77.7 & 77.7 & 54.6 \\
\hline 7 & 1.5 & 185.0 & 117.3 & 73.2 & 73.2 & 58.2 \\
\hline 8 & 1.5 & 207.9 & 111.4 & 49.1 & 49.1 & 48.8 \\
\hline
\end{tabular}


The hygiene limit values are exceeded at points 2, 4, 5, 6, 7 .

Measures: Equip the building site with solid fencing for the stage in question. The height of fencing is $1.8 \mathrm{~m}$ with solid gate wings at the entrance to the construction site.

Figure 13 shows the same acoustic situation but the added fencing of the construction site, Table 15 shows the resulting values.

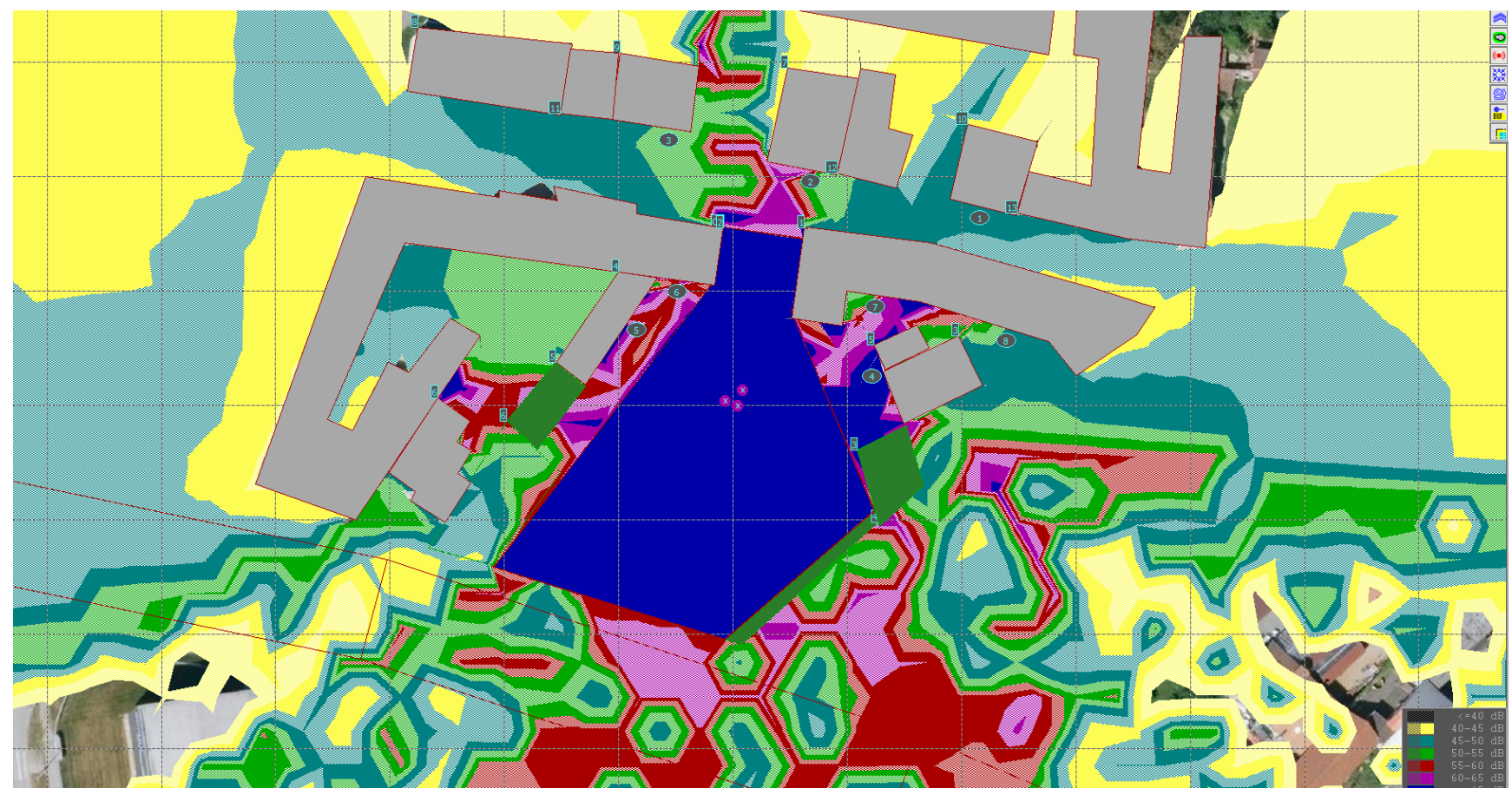

Figure 13. Colour map of isophone bands after considering acoustically significant elements with construction site fencing and a solid gate for pile-driving work in the investigated area.

Table 15. Table of points from the calculation of measured points for earthworks with construction site fencing and a solid gate in the investigated area.

\begin{tabular}{|c|c|c|c|c|c|}
\hline \multirow{2}{*}{ No. } & \multirow{2}{*}{ Height } & \multirow{2}{*}{\multicolumn{2}{|c|}{ Coordinates }} & \multicolumn{2}{|c|}{$\mathrm{LA}_{\mathrm{eq}}(\mathrm{dB})$} \\
\hline & & & & Industry & Total \\
\hline 1 & 1.5 & 203.3 & 132.8 & 48.9 & 48.9 \\
\hline 2 & 1.5 & 173.7 & 139.2 & 62.8 & 62.8 \\
\hline 3 & 1.5 & 148.9 & 146.5 & 50.2 & 50.2 \\
\hline 4 & 1.5 & 184.4 & 105.0 & 66.7 & 66.7 \\
\hline 5 & 1.5 & 143.1 & 113.3 & 56.6 & 56.6 \\
\hline 6 & 1.5 & 150.2 & 119.9 & 54.6 & 54.6 \\
\hline 7 & 1.5 & 185.0 & 117.3 & 58.2 & 58.2 \\
\hline 8 & 1.5 & 207.9 & 111.4 & 48.8 & 48.8 \\
\hline
\end{tabular}

The hygiene limit value was exceeded at point 4 .

Measures: The fulfilment of the hygiene limit for all measurement points can only be ensured by shortening the pile-driving work period. With fencing, the work period is to be shortened to $7.5 \mathrm{~h}=450 \mathrm{~min} /$ day, while without fencing the duration should be $1 \mathrm{~h}=60 \mathrm{~min} /$ day.

The position of the piling rig in the position oriented towards the developed area on Černovická St. is in Figure 14 and the resulting values in Table 16. 


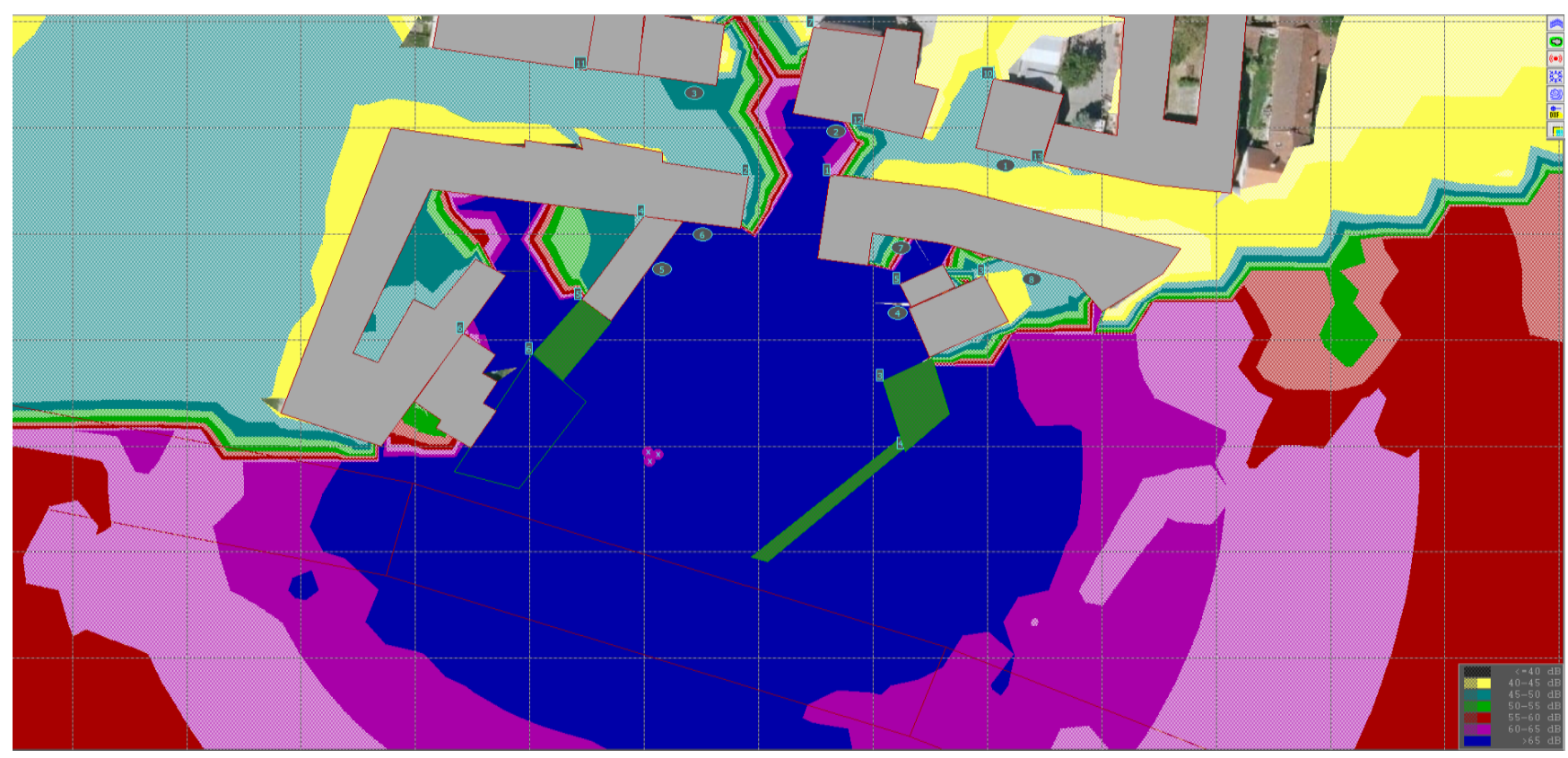

Figure 14. Colour map of isophone bands after considering acoustically significant elements (without construction site fencing or a solid gate) for pile-driving work in the investigated area, with the positions of machines.

Table 16. Table of points from the calculation of measured points for pile-driving work without construction site fencing or a solid gate for pile-driving work in the investigated area, with the positions of machines.

\begin{tabular}{|c|c|c|c|c|c|c|}
\hline \multirow{2}{*}{ No. } & \multirow{2}{*}{ Height } & \multirow{2}{*}{\multicolumn{2}{|c|}{ Coordinates }} & \multicolumn{3}{|c|}{$\mathrm{LA}_{\mathrm{eq}}(\mathrm{dB})$} \\
\hline & & & & Industry & Total & Previous \\
\hline 1 & 1.5 & 203.3 & 132.8 & 45.4 & 54.4 & 48.6 \\
\hline 2 & 1.5 & 173.7 & 139.2 & 67.3 & 67.3 & 71.8 \\
\hline 3 & 1.5 & 148.9 & 146.5 & 47.8 & 47.8 & 50.2 \\
\hline 4 & 1.5 & 184.4 & 105.0 & 69.9 & 69.9 & 77.2 \\
\hline 5 & 1.5 & 143.1 & 113.3 & 73.0 & 73.0 & 77.6 \\
\hline 6 & 1.5 & 150.2 & 119.9 & 72.4 & 72.4 & 77.7 \\
\hline 7 & 1.5 & 185.0 & 117.3 & 67.1 & 67.1 & 73.2 \\
\hline 8 & 1.5 & 207.9 & 111.4 & 45.7 & 45.7 & 49.1 \\
\hline
\end{tabular}

The hygiene limit values are exceeded at points 2, 4, 5, 6, 7. Even the furthest position of the machines from the measurement points does not meet the limit without additional measures.

Measures: The fulfilment of the hygiene limit for all measurement points can only be ensured by shortening the pile-driving work period. With fencing, the pile-driving work period is to be shortened to $7.5 \mathrm{~h}=450 \mathrm{~min} /$ day and without fencing the duration should be $1 \mathrm{~h}=60 \mathrm{~min} /$ day.

Calculation 5: Foundation of the Building, Shallow Foundations-Concreting, Machine: 9, 11

For the noise sources listed in Table 17, the acoustic situation is modeled in Figure 15, the calculation is given in Table 18.

Table 17. Expected sources of construction noise.

\begin{tabular}{ccc}
\hline & Sources of Noise & Sound Power Level (dB) \\
\hline 9. & Concrete mixer truck & 101 \\
11. & Pump & 100 \\
\hline
\end{tabular}




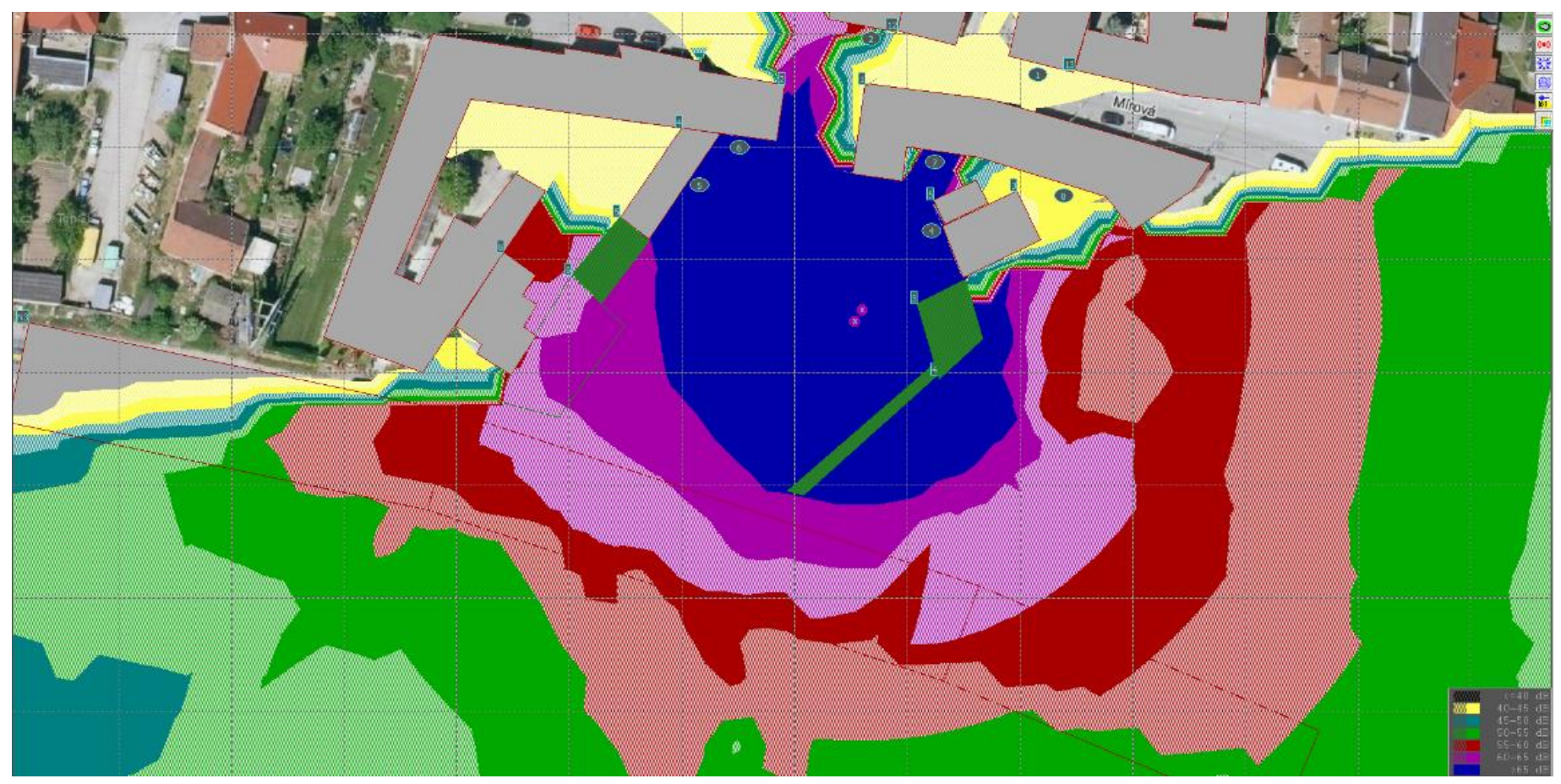

Figure 15. Colour map of isophone bands after considering acoustically significant elements (without construction site fencing or a solid gate) for the concreting of foundations in the investigated area, with the position of machines inside the construction site.

Table 18. Table of points from the calculation of measured points for pile-driving work without construction site fencing or a solid gate in the investigated area, with the position of machines inside the construction site.

\begin{tabular}{cccccc}
\hline \multirow{2}{*}{ No. } & \multirow{2}{*}{ Height } & \multicolumn{2}{c}{ Coordinates } & \multicolumn{2}{c}{ LA $_{\text {eq }}(\mathbf{d B})$} \\
\cline { 5 - 6 } & 1.5 & 203.3 & 132.8 & 41.5 & Industry \\
\hline 1 & 1.5 & 173.7 & 139.2 & 42.1 & 42.1 \\
2 & 1.5 & 148.9 & 146.5 & 42.3 & 71.3 \\
3 & 1.5 & 184.4 & 105.0 & $\mathbf{7 1 . 3}$ & 66.9 \\
4 & 1.5 & 143.1 & 113.3 & $\mathbf{6 6 . 9}$ & 66.9 \\
5 & 1.5 & 150.2 & 119.9 & $\mathbf{6 6 . 8}$ & 66.8 \\
6 & 1.5 & 185.0 & 117.3 & $\mathbf{6 7 . 3}$ & 67.3 \\
7 & 1.5 & 207.9 & 111.4 & 43.0 & 43.0 \\
8 & & & & &
\end{tabular}

Position of machines with the expected layout inside the construction site.

The hygiene limit values are exceeded at points 4, 5, 6, 7 .

Measures: Equip the building site with solid fencing for the stage in question. The height of the fencing is $1.8 \mathrm{~m}$ with solid gate wings at the entrance to the construction site. Acoustic situation with site fencing and full-area gate in Figure 16, resulting values in Table 19. 


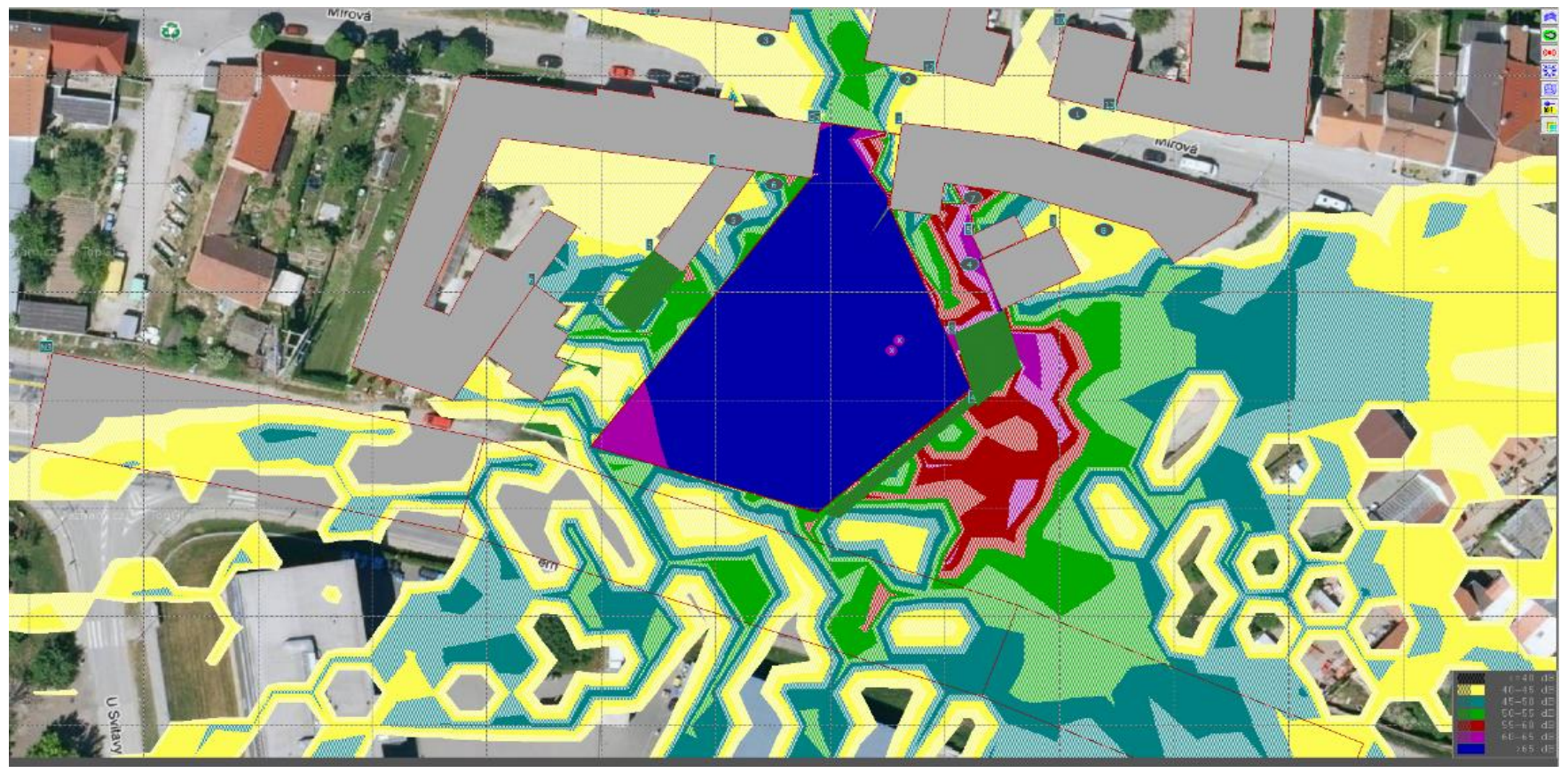

Figure 16. Colour map of isophone bands after considering acoustically significant elements with construction site fencing and a solid gate for the concreting of foundations in the investigated area, with the position of machines inside the construction site.

Table 19. Table of points from the calculation of measured points for the concreting of foundations with construction site fencing and a solid gate in the investigated area, with the position of machines inside the construction site.

\begin{tabular}{|c|c|c|c|c|c|c|}
\hline \multirow{2}{*}{ No. } & \multirow{2}{*}{ Height } & \multirow{2}{*}{\multicolumn{2}{|c|}{ Coordinates }} & \multicolumn{3}{|c|}{$\mathrm{LA}_{\mathrm{eq}}(\mathrm{dB})$} \\
\hline & & & & Industry & Total & Previous \\
\hline 1 & 1.5 & 203.3 & 132.8 & 41.5 & 41.5 & 41.5 \\
\hline 2 & 1.5 & 173.7 & 139.2 & 42.1 & 42.1 & 42.1 \\
\hline 3 & 1.5 & 148.9 & 146.5 & 42.3 & 42.3 & 42.3 \\
\hline 4 & 1.5 & 184.4 & 105.0 & 61.5 & 61.5 & 71.3 \\
\hline 5 & 1.5 & 143.1 & 113.3 & 56.7 & 56.7 & 66.9 \\
\hline 6 & 1.5 & 150.2 & 119.9 & 56.6 & 56.6 & 66.8 \\
\hline 7 & 1.5 & 185.0 & 117.3 & 59.2 & 59.2 & 67.3 \\
\hline 8 & 1.5 & 207.9 & 111.4 & 43.1 & 43.1 & 43.0 \\
\hline
\end{tabular}

After this measure, the hygiene limits for the earthworks stage are fulfilled.

If fencing is not erected for this stage, the work duration needs to be shortened to $3.5 \mathrm{~h}=210 \mathrm{~min} /$ day. The acoustic situation for the position of the machines at the entrance to the construction site is shown in Figure 17 with the resulting values in Table 20.

After this measure, the hygiene limits for the earthworks stage are fulfilled. If fencing is not erected for this stage or if the entry gate needs to be open, eight-hour work shifts need to be used in order to meet the limits at measurement point 2. 


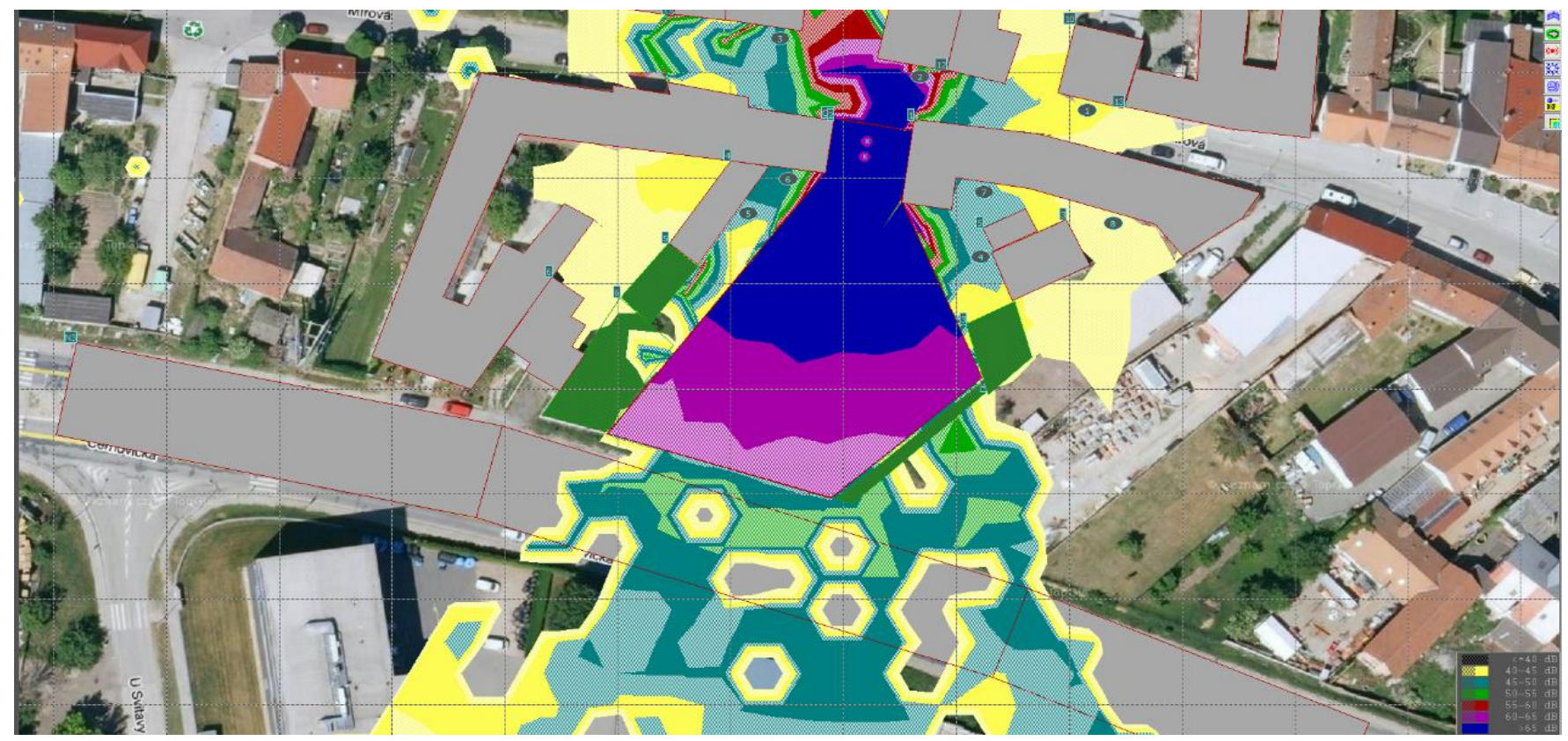

Figure 17. Colour map of isophone bands after considering acoustically significant elements with construction site fencing and a solid gate for the concreting of foundations in the investigated area, with the position of machines inside the construction site.

Table 20. Table of points from the calculation of measured points for the concreting of foundations with construction site fencing and a solid gate in the investigated area, with the position of machines inside the construction site.

\begin{tabular}{ccccccc}
\hline \multirow{2}{*}{ No. } & \multirow{2}{*}{ Height } & \multicolumn{2}{c}{ Coordinates } & \multicolumn{3}{c}{ LA $_{\mathbf{e q}}(\mathbf{d B})$} \\
\cline { 5 - 7 } & & \multicolumn{2}{c}{ Industry } & Total & Previous \\
\hline 1 & 1.5 & 203.3 & 132.8 & 43.4 & 43.4 & 41.5 \\
2 & 1.5 & 173.7 & 139.2 & 65.0 & 65.0 & 42.1 \\
3 & 1.5 & 148.9 & 146.5 & 47.5 & 47.5 & 42.3 \\
4 & 1.5 & 184.4 & 105.0 & 46.2 & 46.2 & 61.5 \\
5 & 1.5 & 143.1 & 113.3 & 61.8 & 61.8 & 56.7 \\
6 & 1.5 & 150.2 & 119.9 & 49.9 & 49.9 & 56.6 \\
7 & 1.5 & 185.0 & 117.3 & 46.7 & 46.7 & 59.2 \\
8 & 1.5 & 207.9 & 111.4 & 42.1 & 42.1 & 43.1 \\
\hline
\end{tabular}

Calculation 6: Rough Superstructure + Material Transfer, Machine: 6, 7

For the noise sources listed in Table 21, the acoustic situation is modeled in Figure 18, the calculation is given in Table 22 .

Table 21. Expected sources of construction noise.

\begin{tabular}{ccc}
\hline & Sources of Noise & Sound Power Level (dB) \\
\hline 6. & Mobile crane & 95 \\
7. & Construction lift & 93 \\
\hline
\end{tabular}




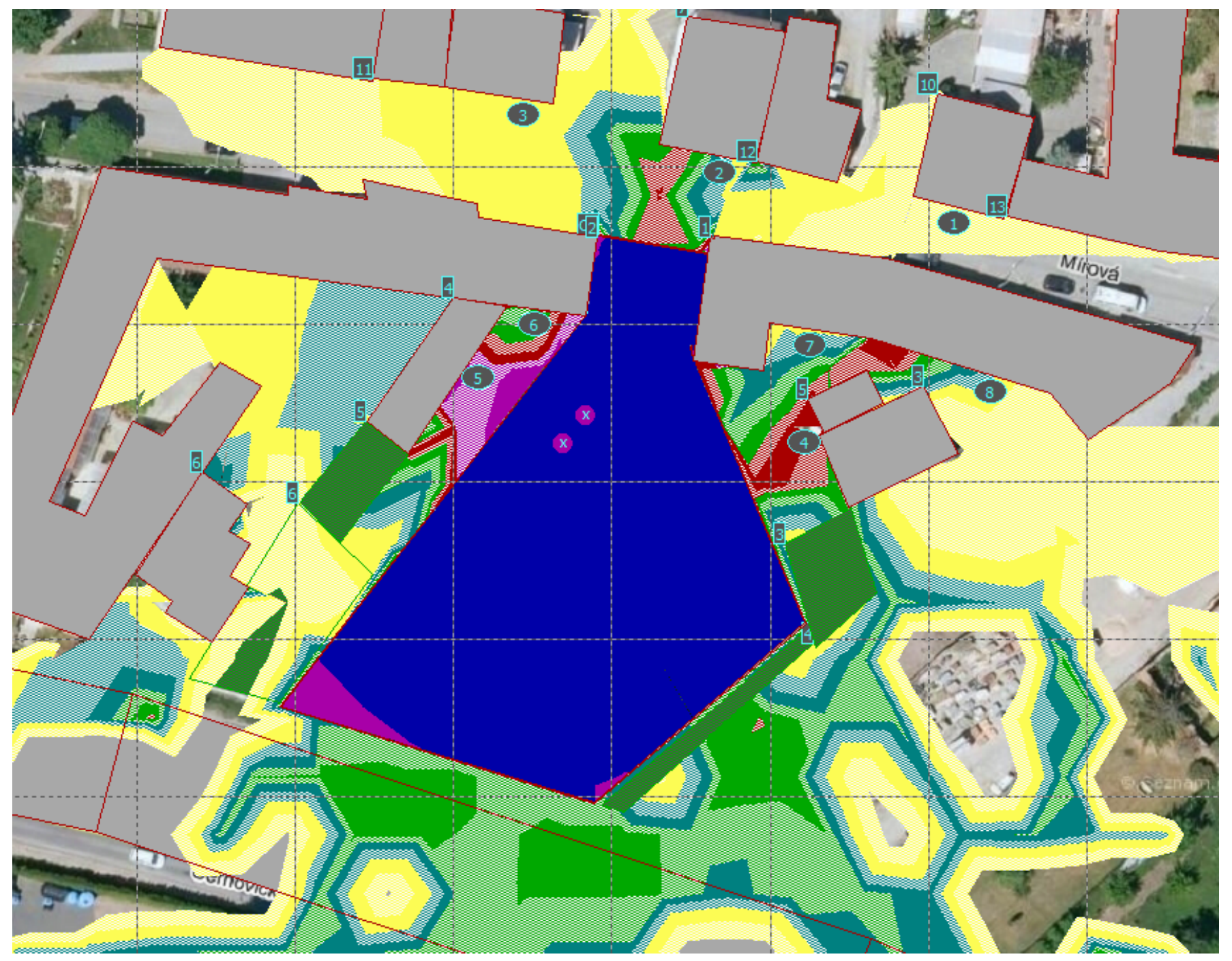

Figure 18. Colour map of isophone bands after considering acoustically significant elements with construction site fencing and a solid gate for superstructure construction in the investigated area, with the position of machines inside the construction site.

Table 22. Table of points from the calculation of measured points for superstructure construction with construction site fencing and a solid gate in the investigated area, with the positions of machines inside the construction site.

\begin{tabular}{cccccc}
\hline \multirow{2}{*}{ No. } & \multirow{2}{*}{ Height } & \multicolumn{2}{c}{ Coordinates } & \multicolumn{2}{c}{ LA $_{\text {eq }}(\mathbf{d B})$} \\
\cline { 5 - 6 } & 1.5 & 203.3 & 132.8 & 40.8 & Industry \\
\hline 1 & 1.5 & 173.7 & 139.2 & 53.8 & 53.8 \\
2 & 1.5 & 148.9 & 146.5 & 44.0 & 44.0 \\
3 & 1.5 & 184.4 & 105.0 & 58.5 & 58.5 \\
4 & 1.5 & 143.1 & 113.3 & 64.3 & 64.3 \\
5 & 1.5 & 150.2 & 119.9 & 52.0 & 52.0 \\
6 & 1.5 & 185.0 & 117.3 & 45.0 & 45.0 \\
7 & 1.5 & 207.9 & 111.4 & 41.7 & 41.7 \\
8 & & & & & \\
\hline
\end{tabular}

The machines are positioned in the riskiest location oriented towards the developed area on Mírová St, considered with fencing, which is always erected in the superstructure construction stage.

In the case that solid fencing is used, the hygiene limits for the superstructure construction stage are fulfilled. 
Calculation 7: Final Landscaping, Machine: 8, 10

For the noise sources listed in Table 23, the acoustic situation is modeled in Figure 19, the calculation is given in Table 24.

Table 23. Expected sources of construction noise.

\begin{tabular}{ccc}
\hline & Sources of Noise & Sound Power Level (dB) \\
\hline 8. & Vibrating roller & 106 \\
10. & Crawler excavators (mini) 0.9-9 tons & 97 \\
\hline
\end{tabular}

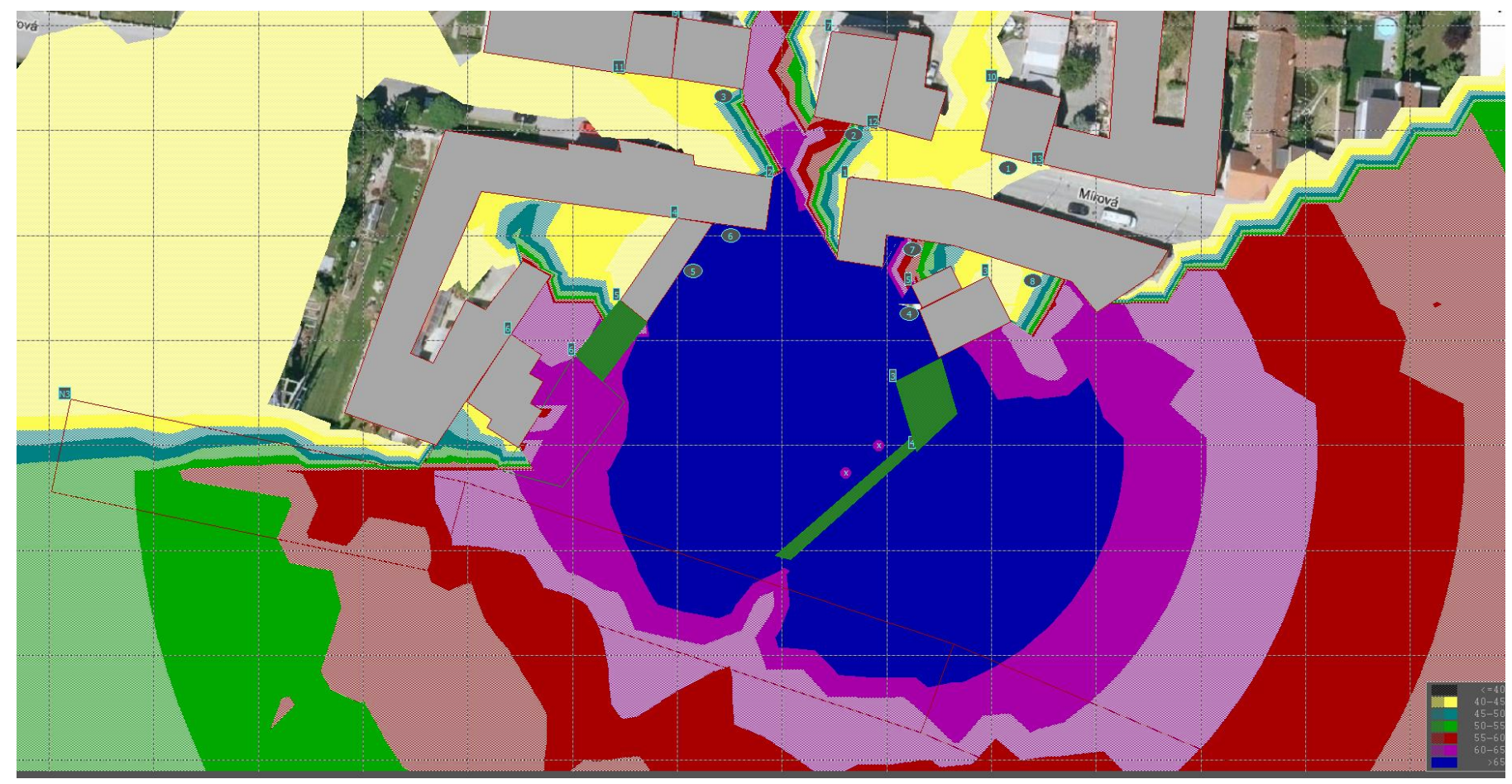

Figure 19. Colour map of isophone bands after considering acoustically significant elements (without construction site fencing or a solid gate) for the final landscaping in the investigated area, with the deployment of both machines.

Table 24. Table of points from the calculation of measured points for final landscaping without construction site fencing or a solid gate for the investigated area, with the deployment of both machines.

\begin{tabular}{ccccccc}
\hline \multirow{2}{*}{ No. } & \multirow{2}{*}{ Height } & \multicolumn{2}{c}{ Coordinates } & \multicolumn{3}{c}{ LA $_{\mathbf{e q}}(\mathbf{d B})$} \\
\cline { 5 - 7 } & & \multicolumn{2}{c}{ Industry } & Total & Previous \\
\hline 1 & 1.5 & 203.3 & 132.8 & 40.7 & 40.7 & 40.8 \\
2 & 1.5 & 173.7 & 139.2 & 58.1 & 58.1 & 65.6 \\
3 & 1.5 & 148.9 & 146.5 & 44.0 & 44.0 & 57.9 \\
4 & 1.5 & 184.4 & 105.0 & 70.4 & 70.4 & 68.9 \\
5 & 1.5 & 143.1 & 113.3 & 67.2 & $\mathbf{6 7 . 2}$ & 74.1 \\
6 & 1.5 & 150.2 & 119.9 & 67.4 & $\mathbf{6 7 . 4}$ & 74.2 \\
7 & 1.5 & 185.0 & 117.3 & 68.3 & $\mathbf{6 8 . 3}$ & 45.0 \\
8 & 1.5 & 207.9 & 111.4 & 43.1 & 43.1 & 41.7 \\
\hline
\end{tabular}

The machines employed for final landscaping do not have to (but can) be deployed simultaneously.

The hygiene limit values are exceeded at points 4, 5, 6, 7 .

Measures: Separate deployment of machines according to Figures 20 and 21. 


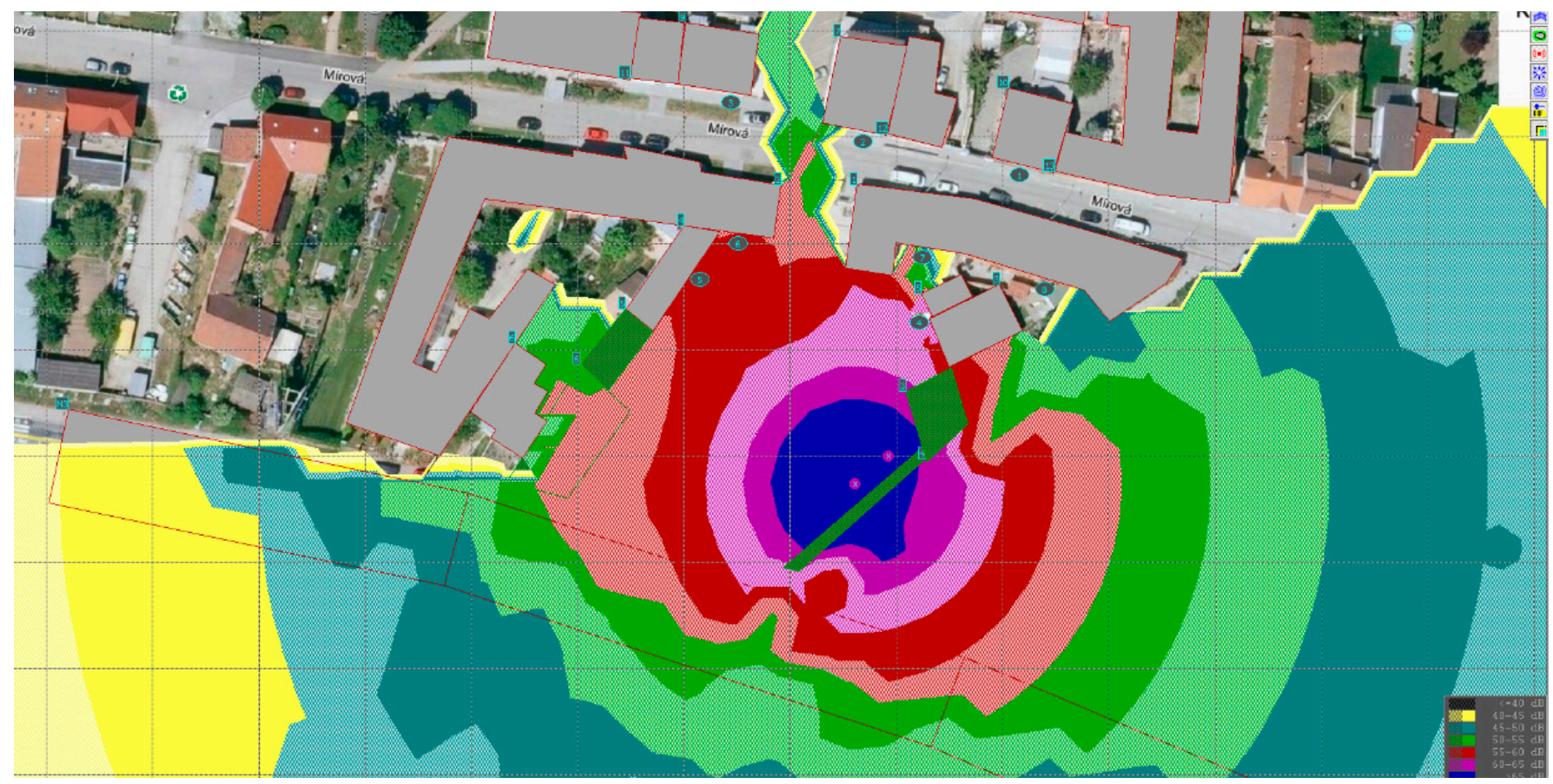

Figure 20. Colour map of isophone bands after considering acoustically significant elements (without construction site fencing or a solid gate) for final landscaping in the investigated area, with the deployment of only the machine for the transfer and deposition of soil.

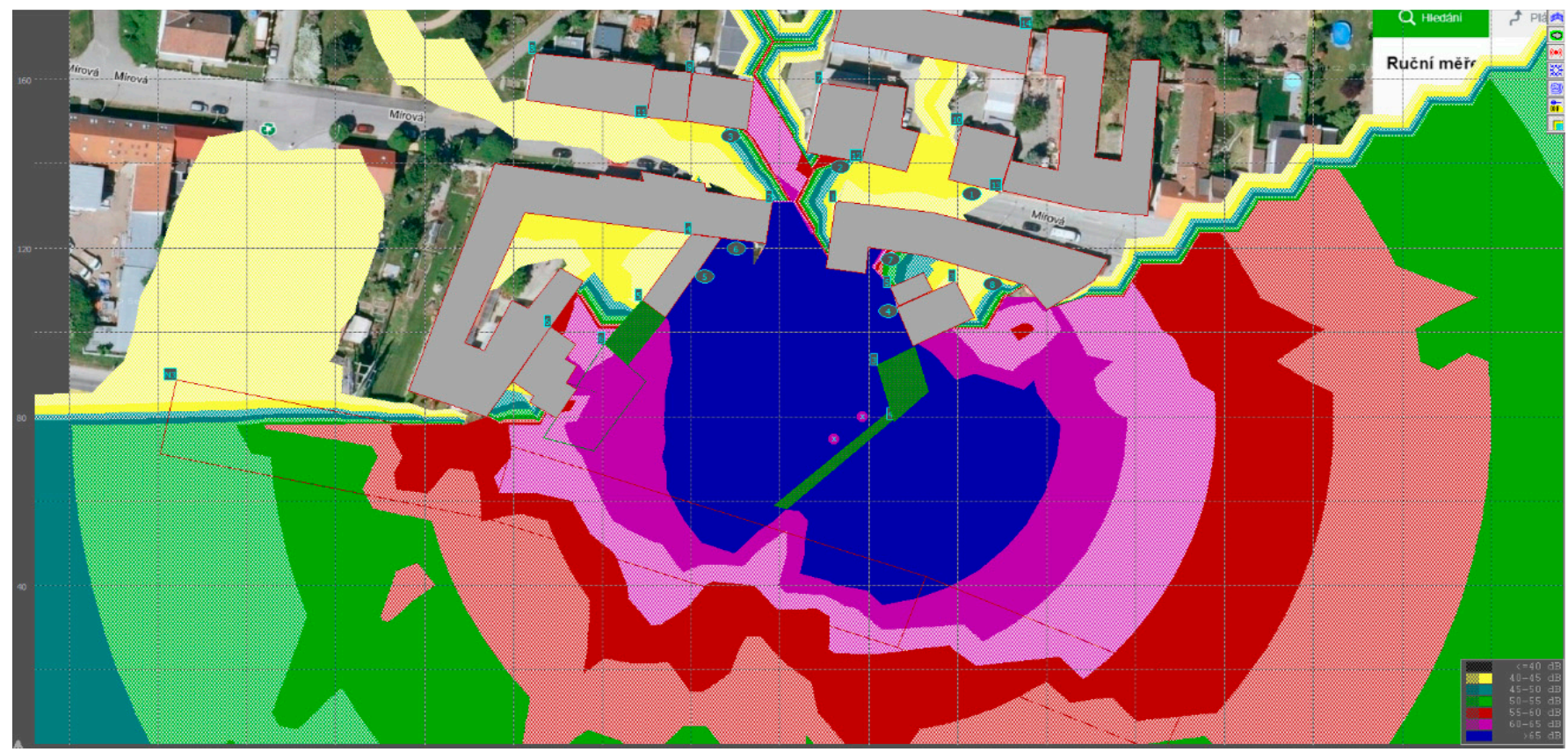

Figure 21. Colour map of isophone bands after considering acoustically significant elements (without construction site fencing or a solid gate) for final landscaping in the area in question, with the deployment of only the compaction machine.

The hygiene limits for the final landscaping stage are fulfilled if the machine for the transfer and deposition of soil is used on its own.

However, if a vibrating roller is simultaneously deployed for the final landscaping work, or even if it is operated independently, the measures involving just independent deployment will not be sufficient to keep noise within the limit values. 
Measures: Leave the $1.8 \mathrm{~m}$ solid fencing with solid entrance gate wings at the construction site erected for the period of final landscaping according to Figure 22 with output values in Table 25.

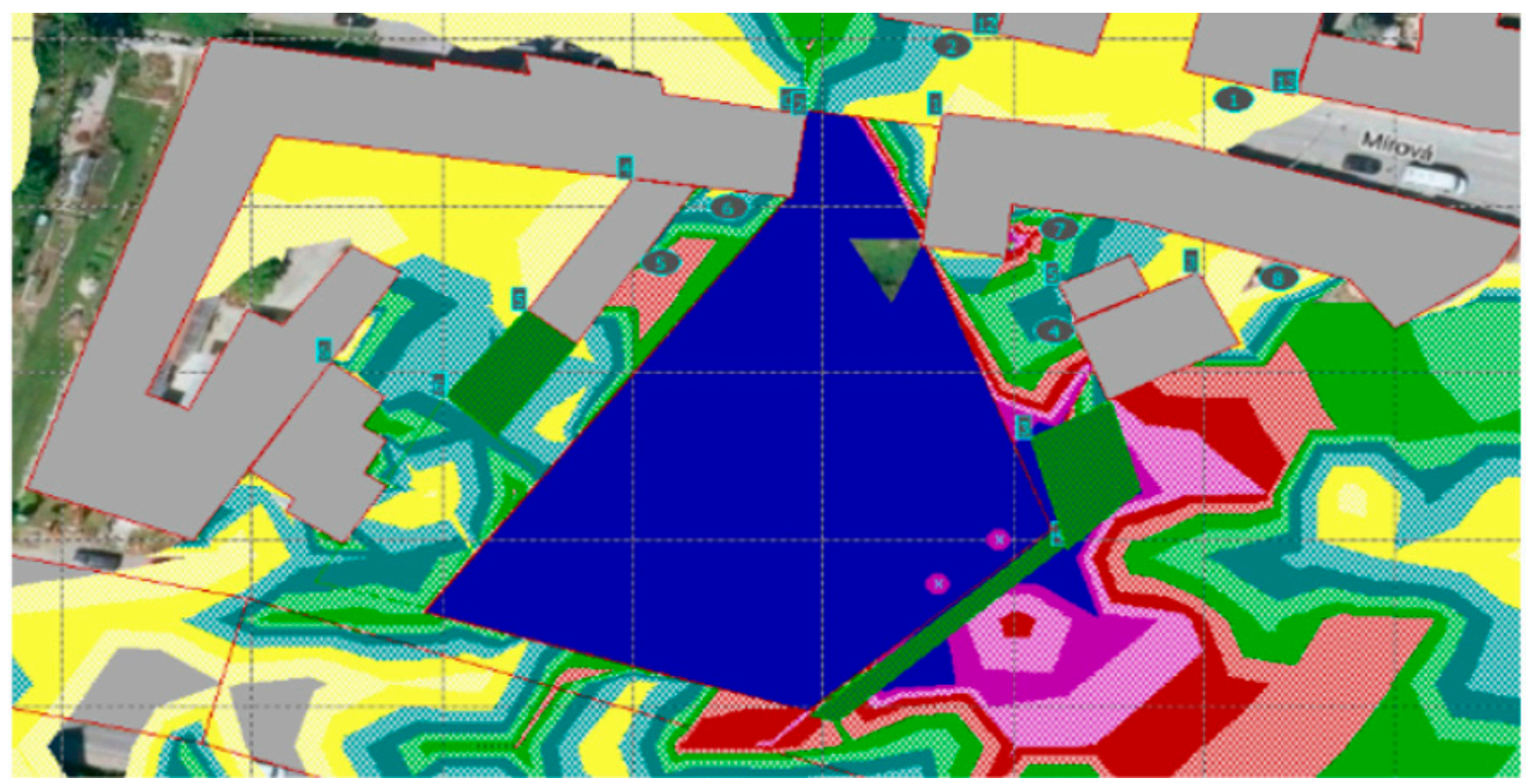

Figure 22. Colour map of isophone bands after considering acoustically significant elements for final landscaping with construction site fencing and a solid gate in the investigated area.

Table 25. Table of points from the calculation of measured points for final landscaping with construction site fencing and a solid gate in the investigated area.

\begin{tabular}{ccccccc}
\hline \multirow{2}{*}{ No. } & \multirow{2}{*}{ Height } & \multicolumn{2}{c}{ Coordinates } & \multicolumn{3}{c}{ LA $_{\mathbf{e q}}(\mathbf{d B})$} \\
\cline { 5 - 7 } & & \multicolumn{2}{c}{ Industry } & Total & Previous \\
\hline 1 & 1.5 & 203.3 & 132.8 & 42.9 & 42.9 & 40.7 \\
2 & 1.5 & 173.7 & 139.2 & 43.7 & 43.7 & 58.1 \\
3 & 1.5 & 148.9 & 146.5 & 44.0 & 44.0 & 44.0 \\
4 & 1.5 & 184.4 & 105.0 & 66.8 & 66.8 & 70.4 \\
5 & 1.5 & 143.1 & 113.3 & 56.7 & 56.7 & 67.2 \\
6 & 1.5 & 150.2 & 119.9 & 44.1 & 44.1 & 67.4 \\
7 & 1.5 & 185.0 & 117.3 & 44.2 & 44.2 & 68.3 \\
8 & 1.5 & 207.9 & 111.4 & 37.1 & 37.1 & 43.1 \\
\hline
\end{tabular}

The limit value was exceeded at point 4.

Measures: If the vibrating roller is used, its activities should be separated from the deployment of other plant, the solid fencing erected previously should be left up and the deployment of the roller should be shortened to $4 \mathrm{~h}=240 \mathrm{~min} /$ day. Without other measures, shorten the duration of processes to $110 \mathrm{~min}$.

\subsubsection{Conclusions of the Noise Study}

In the calculations of this noise study, the expected noise impacts connected with a construction site were determined, with consideration given to the technical stages of the construction process according to the project documentation and the associated use of suitable construction equipment. Seven technical stages were evaluated, in which a total of 11 acoustically dominant machines were considered as a source of noise.

For each of the individual stages, possible sub-measures were evaluated, particularly the separation of excavation work and the removal of excavated material. The option of 
using solid fencing at the construction site was also taken into account, including the use of an entrance gate as an acoustic screen.

In order to ensure compliance with the requirement of NV 272/2011 Coll. and so that sound pressure values do not exceed limit values, especially for both the Mírová St facade lines and the facade line of buildings 25/9, 26/7, 350/7 and 237/11 (which are oriented towards the building site), the following measures are recommended for the sub-processes:

1. Demolition work: Shorten the duration of demolition activities to $1 \mathrm{~h}=60 \mathrm{~min} /$ day; if solid fencing is used as an acoustic screen then $7 \mathrm{~h}=420 \mathrm{~min} /$ day.

2. Earthworks for utility networks: Shorten the duration of excavation activities to $3 \mathrm{~h}=180 \mathrm{~min} /$ day.

3. Earthworks for SO01: Hygiene limits for the earthworks stage are fulfilled if solid fencing is used as an acoustic screen. Without fencing, the work period is to be shortened to $6.5 \mathrm{~h}=390 \mathrm{~min} /$ day.

4. Foundation of the structure-pile-driving: Shorten the duration of pile-driving to $7.5 \mathrm{~h}=450 \mathrm{~min} /$ day in the case of the installation of solid fencing, without the fencing then $1 \mathrm{~h}=60 \mathrm{~min} /$ day.

5. Foundation of the structure-shallow foundations: Hygiene limits for the earthworks stage are fulfilled if solid fencing is employed as an acoustic screen. If fencing is not erected for this stage, the duration of work needs to be shortened to $210 \mathrm{~min} /$ day. If the operation of the construction site will require construction machines to be stabilised near the entrance gate, the hygiene limits for the earthworks stage will be fulfilled when the solid fencing gate is closed. If fencing is not erected for this stage or if the entrance gate needs to be open, eight-hour work shifts need to be used in order to meet the limits at measurement point 2.

6. Superstructure construction: In the case that solid fencing is used, the hygiene limits for the superstructure construction stage are fulfilled.

7. Final landscaping: The hygiene limits for the final landscaping stage are fulfilled if the machine for the transfer and deposition of soil is used on its own. If the vibrating roller is used, its activities should be separated from those of other plant, the solid fencing used for previous stages should be kept up and the deployment of the roller should be shortened to $4 \mathrm{~h}=240 \mathrm{~min} /$ day. If other measures are not used, shorten the period of deployment to $110 \mathrm{~min} /$ day.

To optimise the pre-construction plan, it is recommended that:

- The contractor must consider shortening the duration of deployment of construction machines during a work shift in the schedule for the given construction project by extending the period allotted for the given construction process, so that the total construction time is not affected.

- The need to shorten the duration of plant deployment depends on the simultaneous deployment of other machines, so it is not possible to combine previously evaluated sets of construction machines with other acoustically significant equipment.

- It is recommended that solid fencing be procured and applied throughout the duration of the construction project.

- The acquisition of solid fencing for use as a passive barrier against the spread of noise appears to be financially advantageous, given that this measure affects all processes; see the individual recommendations for processes. This financial cost needs to be included in the budget for site equipment.

- Pay attention to the correct technical installation of the solid fencing, so that the fencing can function as a noise barrier. Pay attention to sealing, particularly at the bottom, to avoid unevenness in line with rough ground.

- Do not consider working from 6:00 to 7:00, from 21:00 to 22:00, or at night from 22:00 to 6:00, work with plant should only be performed during the day from 7:00 to 21:00.

- The contractor should not suddenly extend work shifts: The time spent by workers at the construction site and the duration of the deployment of machinery should be the same every working day. 
- The contractor is obliged to guarantee the regular maintenance of equipment, to choose machines for work in built-up areas which are in the first half of their service life and to check the sound power level of employed machines: The value is indicated on the machine's label.

- In the case of the investigated construction site, the course and duration of the noisiest jobs should be agreed on in advance with the inhabitants of the buildings at Mírová $25 / 9,26 / 7,350 / 7$ and $237 / 11$.

\section{Discussion}

From the presented case study, it is clear that there are many aspects to the assessment of a specific investment and that the quality of the results depends on the quality of the input data. The modelling of the future noise situation in an area where construction site equipment is to be deployed provides a visual and numerical evaluation of noise risk. The trend in changes in the sound pressure values at a measured point when possible measures are used indicates the correct path to the overall conception of the noise study to its producer. Only when several assessed points are evaluated for the effectiveness of anti-noise measures can a proposal be made to include suitable anti-noise measures in the construction plan.

We require full use of working hours during construction. In Table 26, we see a reduction in the use of construction machinery during the work shift, both with the use of active measures and without their use, when we ensure compliance with the limit by shortening the time of work. For the present case study, limiting work would mean using up to $44.35 \%$. In the case of elaboration of a study, design and use of anti-noise measures, it can be increased to $81.25 \%$.

Table 26. Working time with the machine during the work shift.

\begin{tabular}{ccccccc}
\hline Calculation Number & \multicolumn{2}{c}{ Duration of Work during the Day (Minutes) } \\
\hline & \multicolumn{2}{c}{ Required } & \multicolumn{2}{c}{$\begin{array}{l}\text { Without Active } \\
\text { Measures }\end{array}$} & $\begin{array}{c}\text { With Active } \\
\text { Measures }\end{array}$ \\
\hline 1 & 480 & $100 \%$ & 60 & $12.50 \%$ & 420 & $87.50 \%$ \\
2 & 480 & $100 \%$ & 180 & $37.50 \%$ & 180 & $37.50 \%$ \\
3 & 480 & $100 \%$ & 390 & $81.25 \%$ & 480 & $100.00 \%$ \\
4 & 480 & $100 \%$ & 60 & $12.50 \%$ & 450 & $93.75 \%$ \\
5 & 480 & $100 \%$ & 210 & $43.75 \%$ & 480 & $100.00 \%$ \\
6 & 480 & $100 \%$ & 480 & $100.00 \%$ & 480 & $100.00 \%$ \\
7 & 480 & $100 \%$ & 110 & $22.92 \%$ & 240 & $50.00 \%$ \\
TOTAL & \multicolumn{2}{c}{$100 \%$} & & $44.35 \%$ & \multicolumn{2}{c}{$81.25 \%$} \\
\hline
\end{tabular}

In the future, it will be possible to approach other research goals. If there are several case studies, the effectiveness of noise barriers can be analysed, scientists are already addressing this issue in a broader context [33]. Some also address shape adjustment options for greater efficiency of these walls [34-37]. The procedures in the presented case study can also be used to model noise on the construction site in order to determine the noise load of construction managers, which is not dedicated technical or legislative attention $[9,36]$. In the Czech Republic, noise limit values are compared only for direct operation of work machines and for persons in residential buildings in the vicinity of the construction site, not for construction managers. Future analyses should also focus on the use of soundproof barriers and covers for construction machinery $[12,15,24,35,38]$ and multicriteria optimization of own construction schedules [27,39]. There are existing studies on the layout of the construction site in connection with the main construction machines [3,4,40-43], but very little account is taken of machine noise in the optimization $[2,5,44]$. It is possible to continue the research of noise from construction and for the transmission inside the building and the subsequent propagation of noise and vibration in the indoor environment of buildings [23,24,45-48]. 


\section{Conclusions}

The production of a construction site noise study by a contractor within the scope detailed above enables the incorporation of the obtained measures into other documentation for application by contractors in the pre-production and production stages. The sub-measures to be employed for technical processes can be described in a timely fashion in technical instructions and the times and sequences of processes can be adjusted in the time schedule so as not to prolong the "critical path" of the construction period. The budget for construction site equipment costs can be adjusted if it is budgeted by item, while if it is budgeted in terms of percentage cost, it can be revealed in time that the chosen financial sum is inadequate and that the budget needs to be recalculated by item. The construction information model thus, becomes more precise and there is a greater correspondence between the construction plan and the course of its future execution. As we can see from the presented case study, if the noise from construction is not modelled in advance, the construction time can be extended up to twice.

Funding: This research did not receive any external funding.

Institutional Review Board Statement: Not applicable.

Informed Consent Statement: Not applicable.

Data Availability Statement: Not applicable.

Conflicts of Interest: The authors declare no conflict of interest. The funders had no role in the design of the study; in the collection, analyses, or interpretation of data; in the writing of the manuscript, or in the decision to publish the results.

\section{References and Note}

1. Jarský, Č.; Musil, F.; Gašparík, J.; Motyčka, V.; Kovářová, B.; Svoboda, P.; Pospíchal, V.; Vyčítal, M. Preparation and Implementation of Constructions: Construction Technology II, 2nd ed.; Academic Publishing House CERM: Brno, Czech Republic, 2019 ; p. 153. ISBN 978-80-7204-994-3.

2. Kantová, R. Reducing the value of construction site noise by modeling the production space of the building and modifications of technological procedures during construction. 2018.

3. Št'astný, J.; Motyčka, V. Design optimization of lifting mechanisms. In IOP Conference Series: Materials Science and Engineering; IOP Publishing: Bristol, UK, 2019; Volume 1, pp. 1-9. [CrossRef]

4. Š́t'astný, J.; Motyčka, V.; Brandtner, M.; Bř́za, L.; Doubek, R. Monitoring of buildings-monitoring the use of lifting equipment. Czech. J. Civ. Eng. 2018, 2018, 8.

5. Ning, X.; Qi, J.; Wu, C.; Wang, W. Reducing noise pollution by planning construction site layout via a multi-objective optimization model. J. Clean. Prod. 2019, 222, 218-230. [CrossRef]

6. Act. No.258/2000 Coll. on the Protection of Public Health; Prague, Czech Republic, 2000; Volume 2000, p. 1, (amended). Available online: http://ilo.org/dyn/natlex/natlex4.detail?p_lang=en\&p_isn=72639\&p_country=CZE\&p_count=261 (accessed on 11 May 2021).

7. Government Regulation 272/2011 Coll. on the Protection of Health against the Adverse Effects of Noise and Vibration: Version Government Regulation No. 217/2016 Coll; Prague, Czech Republic, 2011; Volume 2011, p. 5. Available online: http:/ /www.ilo.org/dyn/natlex/ natlex4.detail?p_lang=en\&p_isn=91003\&p_country=CZE\&p_count=261 (accessed on 11 May 2021).

8. Ministry of Health-Chief Hygienist of the Czech Republic. HH ČR File no. 62545/2010-OVZ-32.3-1.11.2010 METHODOLOGICAL INSTRUCTIONS for the Unification of the Procedure of Public Health Protection Bodies and Health Institutes in the Performance of State Health Supervision in the Assessment of Noise in the Protected Outdoor Area of Buildings; Ministry of Health-Chief Hygienist of the Czech Republic: Prague, Czech Republic, 2010; Volume 2010, p. 13.

9. Rutkowski, G.; Korzeb, J. Occupational Noise on Floating Storage and Offloading Vessels (FSO). Sensors 2021, 21, 1898. [CrossRef]

10. Noise in the Environment and Its Effect on Human Health. Available online: http://www.vzbb.sk/sk/aktuality/spravy/2011 /hluk.php.www.khsstc.cz (accessed on 5 May 2021).

11. Marcinkowski, A.; Kopania, J. Environmental Performance of Noise Reduction System in Cogeneration Plants-A Life Cycle Assessment Study. Energies 2021, 14, 1324. [CrossRef]

12. Kumar, S.; Lee, H.P. The Present and Future Role of Acoustic Metamaterials for Architectural and Urban Noise Mitigations. Acoustics 2019, 1, 590-607. [CrossRef]

13. Kliková, A. Building permits of selected recreational buildings from the point of view of the building act. In Proceedings of the Public Recreation and Landscape Protection-With Sense Hand in Hand; Mendel University in Brno: Krtiny, Czech Republic, 2019; pp. 49-50. 
14. Vlčková, J.; Henková, S. Safety versus cost of linear structures in public procurement. In Advances and Trends in Engineering Sciences and Technologies II; CRC Press Balkema: Vysoke Tatry, Slovakia, 2017; pp. 673-678.

15. Mohapl, M.; Pražáková, J.; Hejl, M. Impact on Total Costs and Construction Period of Residential Buildings in Prague. In IOP Conference Series: Earth and Environmental Science; Institute of Physics Publishing: Prague, Czech Republic, 2019; Volume 221, p. 012004. [CrossRef]

16. Venkrbec, V.; Brandtner, M. Selection of Lifting Mechanism for Small-Scale Construction Project: A Comparative Method Based on Building Volume and an Automated Schedule. In IOP Conference Series: Earth and Environmental Science; Institute of Physics Publishing: Prague, Czech Republic, 2019; Volume 221, p. 012092. [CrossRef]

17. Venkrbec, V.; Galić, M.; Klanšek, U. Construction process optimization-Review of methods, tools and applications. Gradevinar 2018, 70, 593-606. [CrossRef]

18. Brandtner, M.; Venkrbec, V. Non-graphical data structure for the purpose of BIM-based Life Cycle Assessment: Methodology for the Czech environment. In IOP Conference Series: Earth and Environmental Science; IOP Publishing: Bristol, UK, 2020; Volume 609, p. 012048. [CrossRef]

19. Majer, R.; Ellingerová, H.; Gašparík, J. Methods for the Calculation of the Lost Profit in Construction Contracts. Buildings 2020, 10, 74. [CrossRef]

20. Gasparik, J.; Funtik, T.; Gasparík, M.; AlAmro, B.; GaParík, J.; Funtík, T.; GaParík, M. Continuing Increasing of Quality Management Level in Construction Company Using Excellence Model with Software Support. In Proceedings of the 35th International Symposium on Automation and Robotics in Construction (ISARC), Berlin, Germany, 20-25 July 2018 ; pp. 199-205.

21. Kantová, R. Construction Machines as a Source of Construction noise. Procedia Eng. 2017, 190, 92-99. [CrossRef]

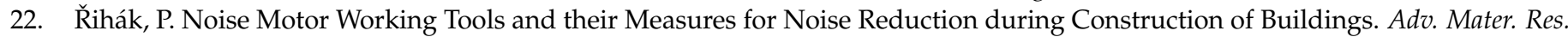
2014, 1041, 424-427. [CrossRef]

23. Nečasová, B.; Liška, P.; Šlanhof, J.; Sedlák, P.; Motyčka, V. Long adhesive joints in façade applications exposed to wind suction. Proc. Inst. Mech. Eng. Part E J. Process. Mech. Eng. 2020, 234, 488-498. [CrossRef]

24. Liška, P.; Nečasová, B.; Šlanhof, J.; Schmid, P.; Motyčka, V. Impact of manufacturing imperfections and surface defects on stress-strain behaviour of flexible adhesive joints. Proc. Inst. Mech. Eng. Part E J. Process. Mech. Eng. 2020, 234, 499-510. [CrossRef]

25. Fišarová, Z.; Kalousek, L.; Šlanhof, J.; Motyčka, V. Design of the flooring termination detail at the wall base from the historical and contemporary point of view. Akustika 2020, 35, 9-22. Available online: https://www.journalakustika.com/journal/volume-35-2/ (accessed on 28 January 2021).

26. Elmenhorst, E.-M.; Griefahn, B.; Rolny, V.; Basner, M. Comparing the Effects of Road, Railway, and Aircraft Noise on Sleep: Exposure-Response Relationships from Pooled Data of Three Laboratory Studies. Int. J. Environ. Res. Public Health 2019, 16, 1073. [CrossRef] [PubMed]

27. Ciaburro, G.; Iannace, G. Improving Smart Cities Safety Using Sound Events Detection Based on Deep Neural Network Algorithms. Informatics 2020, 7, 23. [CrossRef]

28. Iannace, G.; Berardi, U.; Ciaburro, G.; D'orazio, D.; Trematerra, A. Mini-wind turbine noise measured inside near-by houses. Can. Acoust. 2020, 48, 18-20.

29. Iannace, G. Wind turbines noise measurements inside homes. Build. Acoust. 2018, 25, 339-350. [CrossRef]

30. hluk+. Available online: https://www.hlukplus.cz/ (accessed on 20 September 2019).

31. Mapy.cz. Available online: https:/ / www.cuzk.cz/ (accessed on 20 September 2019).

32. EU. Directive 2000/14/EC of the European Parliament and of the Council of 8 May 2000 on the Approximation of the Laws of the Member States Relating to the Noise Emission in the Environment by Equipment for Use Outdoors; EU: Brusel, Belgium, 2000; Volume 2000.

33. Sohrabi, S.; Gómez, T.P.; Garbí, J.R. Suitability of Active Noise Barriers for Construction Sites. Appl. Sci. 2020, 10, 6160. [CrossRef]

34. Zhaomeng, W.; Meng, L.K.; Priyadarshinee, P.; Pueh, L.H. Applications of noise barriers with a slanted flat-tip jagged cantilever for noise attenuation on a construction site. J. Vib. Control. 2017, 24, 5225-5232. [CrossRef]

35. Kwon, N.; Park, M.; Lee, H.-S.; Ahn, J.; Shin, M. Construction Noise Management Using Active Noise Control Techniques. J. Constr. Eng. Manag. 2016, 142, 04016014. [CrossRef]

36. Lee, S.C.; Kim, J.H.; Hong, J.Y. Characterizing perceived aspects of adverse impact of noise on construction managers on construction sites. Build. Environ. 2019, 152, 17-27. [CrossRef]

37. Huang, X.; Zou, H.; Qiu, X. Effects of the Top Edge Impedance on Sound Barrier Diffraction. Appl. Sci. 2020, 10, 6042. [CrossRef]

38. Vlčková, J.; Venkrbec, V.; Henková, S.; Chromý, A. Protection of Workers and Third Parties during the Construction of Linear Structures. In IOP Conference Series: Earth and Environmental Science; IOP Publishing: Bristol, UK, 2017; Volume 95, p. 062003. [CrossRef]

39. Kwon, N.; Song, K.; Lee, H.-S.; Kim, J.; Park, M. Construction Noise Risk Assessment Model Focusing on Construction Equipment. J. Constr. Eng. Manag. 2018, 144, 04018034. [CrossRef]

40. Motyčka, V.; Klempa, L. Scheduling of tower cranes on construction sites. In Advances and Trends in Engineering Sciences and Technologies III; Taylor and Francis Group: London, UK, 2016; pp. 567-573.

41. Gašparík, J.; Bažík, P.; Motyčka, V. Efficient Method of an Optimal Construction Company Supplier Selection Supported by Software. In Proceedings of the ENTRENOVA-ENTerprise REsearch InNOVAtion Conference, 10-12 September 2020; Volume 6, pp. 636-647, (Virtual Conference). 
42. Bistak, A.; Hulinova, Z.; Nestiak, M.; Gasparik, J. The Use of Computer Simulation in Preparation of Construction Works Carried Out by Helicopters. In IOP Conference Series: Materials Science and Engineering; IOP Publishing: Bristol, UK, 2019; Volume 603, p. 032037. [CrossRef]

43. Hyun, H.; Park, M.; Lee, D.; Lee, J. Tower Crane Location Optimization for Heavy Unit Lifting in High-Rise Modular Construction. Buildings 2021, 11, 121. [CrossRef]

44. Kantová, R.; Motyčka, V. Construction Site Noise and its Influence on Protected Area of the Existing Buildings. Adv. Mater. Res. 2014, 1041, 419-423. [CrossRef]

45. Whitman, J.; Deshpande, A.; Zech, W.; Perez, M. Construction Site Utilization Planning: A Process Based upon Industry Best Practices. CivilEng 2021, 2, 309-324. [CrossRef]

46. Petroutsatou, K.; Apostolidis, N.; Zarkada, A.; Ntokou, A. Dynamic Planning of Construction Site for Linear Projects. Infrastructures 2021, 6, 21. [CrossRef]

47. Kim, M.; Ryu, H.-G.; Kim, T.W. A Typology Model of Temporary Facility Constraints for Automated Construction Site Layout Planning. Appl. Sci. 2021, 11, 1027. [CrossRef]

48. Rodríguez, R.; Bascompta, M. Vibration Analysis and Empirical Law Definition for Different Equipment in a Civil Construction. Appl. Sci. 2020, 10, 4689. [CrossRef] 